\title{
Consensus
}

\section{Chinese Consensus on Diagnosis and Treatment of Hepatic Encephalopathy}

\author{
Chinese Expert Committee on Hepatic Encephalopathy
}

$\mathrm{H}$ epatic encephalopathy (HE) is a complex, neuropsychiatric abnormality that occurs as a consequence of metabolic disorders in patients with hepatic insufficiency. The pathogenesis is complex with a strong prognosticator of death. To standardize the clinical management of HE, relevant new data were reviewed and assessed by Chinese Committee of Experts on Hepatic Encephalopathy in China and was discussed and debated extensively. Then the consensus on the management of HE was developed. The final recommendations are based on the data available at the time of production of the document and may be updated with pertinent scientific developments at a later time. All the discussion was organized by the editorial board of Chinese Journal of Experimental and Clinical Infectious Diseases (Electronic Edition), Chinese Journal of Liver Diseases (Electronic Edition) and Infection International (Electronic Edition). The evidence gradings in the consensus are listed in Table 1.

\section{CONCEPT AND CLINICAL CLASSIFICATION OF HE}

\section{Definition}

Hepatic encephalopathy is defined as a spectrum of neuropsychiatric abnormalities in patients with severe liver dysfunction (including acute or chronic liver failure) or portosystemic venous shunts after exclusion of other known brain diseases, which has potential reversibility. Its clinical features can be extensive and broad neuropsychiatric disorders, ranging from subtle deficits in central nervous system function (in mild cases) that can be detected only through intelligence or electrophysiological tests of personality changes, abnormal behavior, mental deterioration or even different levels of disturbance of consciousness or coma (in severe cases). The so-called hepatic coma is

Correspondence: Jun Cheng, Institute of Infectious Diseases, Beijing Ditan Hospital, Capital Medical University; 8 East Jingshun Street, Chaoyang District, Beijing 100015, China

Tel: +86-10-84322006; Fax: +86-10-84397196; E-mail: jun.cheng. ditan@gmail.com just a serious phase of HE.

\section{Clinical subtypes}

According to the classification proposed in the World Congress of Gastroenterology 1998 in Vienna, hepatic encephalopathy is subdivided in type A, B and C. ${ }^{1}$

Type A (acute) : HE associated with acute liver failure (fulminant hepatic failure, FHF) or subacute liver failure. After occurrence of HE, encephalopathic symptoms usually occured within two weeks in the former case and 2-12 weeks in the later case.

Type B (bypass) : HE is caused by portal-systemic shunting without associated intrinsic liver disease, with normal liver histology. The clinical manifestation is the same as HE associated with liver cirrhosis. This portosystemic venous shunting can be spontaneous or caused by surgical or interventional operations, such as the portosystemic venous shunting caused by congenital vascular malformation, intrahepatic and extrahepatic portal vein obstructions (including the embolism or thrombosis of portal vein and its branches caused by trauma, carcinoid, myeloproliferative diseases and other diseases) and the portal hypertension resulting from lymphoma, metastatic tumor and cholangiocarcinoma oppression.

Type C (cirrhosis): HE occurs in patients with cirrhosis. It is the most common type of HE, often with portal hypertension and/or portosystemic venous shunting. Liver failure is the main cause of encephalopathy, followed by portosystemic venous shunting. According to the severity of clinical symptoms, type-C HE is subdivided into minimal HE (MHE) or subclinical encephalopathy and symptomatic HE (SHE) (Table 2).

In China, most $\mathrm{HE}$ patients are type-C, which occured based on chronic liver disease and cirrhosis and often with portal hypertension and portosystemic venous shunting. HE of type A and type B are in relatively small number.

\section{PATHOGENESIS}

A number of theories have been proposed to explain the development of hepatic encephalopathy in patients 
Table 1. Grading of evidences

\begin{tabular}{cl}
\hline Levels of evidence & Descriptions \\
\hline A & Data derived from multiple randomized clinical trials or meta-analysis \\
B & Data derived from a single randomized trial, or nonrandomized studies. \\
C & Only consensus opinion of experts, case studies \\
\hline
\end{tabular}

Table 2. Subtypes of type C HE

\begin{tabular}{|c|c|c|}
\hline Subtypes & & Definitions \\
\hline MHE & \multicolumn{2}{|c|}{$\begin{array}{l}\text { No demonstrating clinically-overt cognitive dysfunction, mild cognitive abnormalities only recognizable with psychometric or } \\
\text { neurophysiologic tests }\end{array}$} \\
\hline \multirow[t]{7}{*}{ SHE } & \multicolumn{2}{|c|}{ Main abnormality is the cognitive, mental and movement disorders. It is subcategorized into two types: episodic and persistent } \\
\hline & Episodic HE $\quad$ Precipitated & $\begin{array}{l}\text { Excessive dietary protein, gastrointestinal bleeding, constipation, infection, } \\
\text { paracentesis, hypokalemia (often as a result of large diuretic use) and } \\
\text { transjugular intrahepatic portal-systemic shunt (TIPS) }\end{array}$ \\
\hline & Spontaneous & Occurring without obvious precipitating factors \\
\hline & Recurrent & Occurring more than 2 times within 1 year \\
\hline & Persistent HE & Equal to West-Haven 1 \\
\hline & Severe HE & Equal to West-Haven 2-3 \\
\hline & Treatment-dependent HE & $\begin{array}{l}\text { Quickly relieved through treatment, but soon recurrent after stopping } \\
\text { treatment }\end{array}$ \\
\hline
\end{tabular}

with cirrhosis. But so far, the pathogenesis of HE has not yet been fully elucidated. Due to acute and chronic liver failure and/or porto-systemic venous shunting, the neurotoxic substances from intestinal veins will bypass the liver and directly enter the heart via another route without undergoing first-pass detoxification by the liver. Then the neurotoxic substances may gain entry into brain through the blood-brain barrier, and result in the dysfunction of the central nervous system. The hyperammonemia, a kind of neurotoxic substances, is recognized as one of the most critical factors, ${ }^{2}$ especially in $\mathrm{HE}$ associated with chronic liver disease and cirrhosis (and/or with portosystemic venous shunting). All factors contributing to hyperammonemia include the increasing production of ammonia, the decreased mass of functioning hepatocytes, resulting in fewer opportunities for ammonia to be detoxified or portosystemic shunting diverting ammonia-containing blood away from the liver to systemic circulation. Ammonia has multiple neurotoxic effects, such as impairment of energy utilization in brain, impact of the balance between the central excitatory neurotransmitters (glutamate) and inhibitory neurotransmitters (such as glutamine, gama-aminobutyric acid, GABA), which resulted in central inhibition. Other hypothesis has also been postulated. For instance, false neurotransmitters (octopamine and phenylethanolamine) replacing the normal neurotransmitters which results in neurotransmission disorder. Reduced concentrations of branched-chain amino acids (leucine, isoleucine and valine) and increased concentrations of aromatic amino acids (phenylalanine, tyrosine and tryptophan) may promote hepatic encephalopathy by causing the production of false neurotransmitters. Benzodiazepines exert their depressant effects on the central nervous system by interacting with high-affinity binding sites on $\gamma$-aminobutyric acid-benzodiazepine receptor complex. Swelling brain cells, dysfunctional astrocytes, neurotoxic effects of mercaptans, shortchain fatty acid and manganese deposition in the basal ganglia may contribute to the pathogenesis of hepatic encephalopathy. ${ }^{3}$

\section{COMMON PRECIPITATING FACTORS}

In HE cases with type-A, the basic liver injury was acute liver failure (fulminant hepatic failure, FHF) or subacute liver failure. A large number of liver cells were damaged and the gut-derived toxin could not be effectively removed, resulting in dysfunction of central nervous system. Type-A HE is a kind of endogenous HE, also known as non-ammonia encephalopathy, and often has no definite precipitating factors. Patients with simple type-B HE is rare in China. As for type-C HE, associated with chronic liver failure or portosystemic venous shunting, the detoxicating function of liver reduces. Once the production of toxicants increases and surpasses the compensatory liver detoxicating ability, then type-C HE occurs, which is largely related with the following precipitating factors.

\section{Excessive intake of nitrogenous foods}

Patients with chronic liver failure or portosystemic venous shunting have a poor tolerance with protein foods, especially animal protein. The overload of protein in intestinal tract will produce a large amount of ammonia and aromatic amino acid, which will cause HE. Oral ammonium salt, urea, methionine and other nitrogenous substances can increase the absorption 
of nitrogen substances, which will result in hyperammonia and cause HE.

\section{Gastrointestinal bleeding}

Massive blood (every $100 \mathrm{ml}$ blood is equivalent to an intake of 15-20 g protein) in gastrointestinal tract results in increased ammonia and nitrogen absorption from the gut. Meanwhile, the leucine and valine increase in blood, which will stimulate the increase of activity of branched chain amino acid dehydrogenase and enhance branched chain amino acid decomposition, aggregating the ratio imbalance between branched chain amino acid and aromatic amino acid. Hemorrhagic hypovolemia, cerebral ischemia and hypoxia can also increase the sensitivity of central nervous system to ammonia and other toxin.

\section{Infection}

Spontaneous bacterial peritonitis, pneumonia, urinary tract infection and bacteremia can enhance tissue catabolism and increase blood ammonia levels, which can further cause endotoxemia, aggravate liver damage and increase the blood-brain barrier permeability and precipitate HE.

\section{Electrolyte imbalance}

Hyponatremia can affect intracellular and extracellular osmolality and cause brain edema, thus inducing HE; hypokalemia is often associated with metabolic alkalosis. Diuretic therapy and abdominal paracentesis to remove a large volume of fluid can also cause alkalosis, which may facilitate the conversion of $\mathrm{NH}_{4}^{+}$to $\mathrm{NH}_{3} . \mathrm{NH}_{3}$ is more easily absorbed from the intestine and passes through the blood-brain barrier and induces HE.

\section{Azotemia}

The hypovolemia caused by a variety of reasons, such as anorexia, diarrhea or liquid intake limitation, and large dosage of diuretics application or abdominal paracentesis can all induce pre-renal azotemia, hepatorenal syndrome or renal azotemia, which may also caused by other reasons. All these factors contribute to elevated blood ammonia levels.

\section{Constipation}

Constipation can prolong the exposurion of ammonia and other intestinal derived toxin to intestinal mucosal, which increases the absorption of these toxic substance.

\section{Hypoglycemia}

Hypoglycemia could decrease the capability of intracephalic detoxification for ammonia and other intestinal derived toxin.

\section{Sedative}

Sedative and hypnotic can directly combine with GABA-benzodiazepine receptor in brain, thus inhibiting the brain function and worsen hepatic encephalopathy.

\section{CLINICAL MANIFESTATIONS AND STAGING}

HE clinical manifestations vary significantly according to the nature of underlying diseases as well as the degree, speed and reason of liver cells damage. It has no significantly different features from other metabolic encephalopathies. The early manifestation is MHE, usually without clear clinical symptoms, which can be tested only by neuropsychological and intelligent test. MHE can further develop into SHE. Type-A HE generally occurs on the basis of acute liver failure, and patients often quickly occur a deep coma or even die from mild confusion in a few days after type-A HE, accompanied by such manifestations of acute liver failure as jaundice, bleeding, prothrombin time activity (PTA) reduction. Features of type-C HE are chronic recurrent episodes of altered mental state, such as behavior changes and even stupor and coma, often accompanied by increased muscle tone, tendon hyperreflexia, asterixis, positive ankle clonus, Babinski sign and other nerve system abnormalities. In the early days, the presentation of encephalopathy in most patients is recurrent and then become persistent, which often accompanied by the manifestations of chronic liver damage and cirrhosis. Usually, excessive dietary protein is a provocative factor, but type-C HE may occur spontaneously or after stopping HE treatment.

According to the degree of consciousness disturbance, nervous system manifestations and EEG changes of the patients and reference to Practical Internal Medicine, $\mathrm{HE}$ can be divided into five stages $(0-4)$, but each stage may overlap or transfer from one stage to the next stage (Table 3 ). ${ }^{4}$

Moreover, the extensively applied West-Haven $\mathrm{Scale}^{2}$ (see Appendix 1) in foreign countries can be used to analyze patients neuropsychiatric condition, and Glasgow Coma Scale ${ }^{2}$ (see Appendix 2) to analyze the degree of patients disturbance of consciousness and clinical hepatic encephalopathy staging scale (CHESS) (see Appendix 8) to analyze the severity of HE. But recently, Hassanein et al launched a more objective, accurate and operational method, hepatic encephalopathy scoring algorithm (HESA) ${ }^{5}$ (see Appendix 3) to reflect the neuropsychiatric status of patients. 
Table 3. Clinical staging indicators of $\mathrm{HE}$

\begin{tabular}{|c|c|c|c|}
\hline Stages & $\begin{array}{l}\text { Degrees of cognitive abnormalities and abnormal } \\
\text { personality and behavior }\end{array}$ & Neurologic system signs & EEG abnormalities \\
\hline $\begin{array}{l}\text { Stage } 0 \\
\text { (MHE/subclinical) }\end{array}$ & $\begin{array}{l}\text { No personality or behavior abnormality; only } \\
\text { mild cognitive abnormalities recognizable with } \\
\text { psychometric or neurophysiologic tests }\end{array}$ & None & Normal wave $\alpha$ rhythm \\
\hline $\begin{array}{l}\text { Stage } 1 \\
\text { (Prodromal stage) }\end{array}$ & $\begin{array}{l}\text { Mild personality changes or abnormal behavior, such } \\
\text { as euphoric excitement or depressed with few words; } \\
\text { scruffy or defecating indiscriminately; unclear and } \\
\text { slow talks but accurate response; inattetive, insomnia } \\
\text { or inverted sleep pattern (sleeping in daytime and } \\
\text { awake at night) }\end{array}$ & Asterixis can be detected & $\begin{array}{l}\text { Irregular background } \\
\text { activity ( } \alpha \text { and } \theta \text { rhythms) }\end{array}$ \\
\hline $\begin{array}{l}\text { Stage } 2 \\
\text { (Precoma stage) }\end{array}$ & $\begin{array}{l}\text { Chiefly sleep disorders and mental confusion; } \\
\text { obvious inversion of sleep pattern and drowsiness; } \\
\text { slow response; intermittent disorientation, usually } \\
\text { regarding time; gross deficits in ability to perform } \\
\text { mental tasks; slurred speech; writing disorders; } \\
\text { inappropriate behavior; even hallucinations, fear and } \\
\text { rage; may have involuntary movements or ataxia }\end{array}$ & $\begin{array}{l}\text { Sthenic tendon reflexes and } \\
\text { muscle tone, positive asterixis } \\
\text { and ankle clonus and Babinski } \\
\text { signs }\end{array}$ & $\begin{array}{l}\text { Continual } \theta \text { rhythms, } \\
\text { occasional with } \delta \text { rhythms }\end{array}$ \\
\hline $\begin{array}{l}\text { Stage } 3 \\
\text { (Lethargy stage) }\end{array}$ & $\begin{array}{l}\text { Mainly lethargy or mental confusion, but can be } \\
\text { aroused, often with confusion or hallucinations and } \\
\text { gross disorientation }\end{array}$ & $\begin{array}{l}\text { Sthenic tendon reflexes and } \\
\text { muscle tone, asterixis and ankle } \\
\text { clonus still may be positive. } \\
\text { Positive Babinski signs }\end{array}$ & $\begin{array}{l}\text { Ordinary } \theta \text { rhythms } \\
\text { with transient polyphase } \\
\text { rhythms containing spike } \\
\text { rhythms and slow rhythms }\end{array}$ \\
\hline $\begin{array}{l}\text { Stage } 4 \\
\text { (Coma stage) }\end{array}$ & $\begin{array}{l}\text { Coma (complete loss of consciousness, but can not be } \\
\text { aroused) with or without reaction to painful stimuli; } \\
\text { no reaction to various stimuli in time of deep coma }\end{array}$ & $\begin{array}{l}\text { In time of light coma, sthenic } \\
\text { tendon reflex and muscular tone } \\
\text { and positive ankleclonus can be } \\
\text { detected; in time of deep coma, } \\
\text { no asterixis signs can be checked } \\
\text { and various reflex disappears }\end{array}$ & $\begin{array}{l}\text { Continual } \delta \text { rhythms with } \\
\text { occasional } \delta \text { rhythms; a } \\
\text { large amount of polyphase } \\
\text { rhythms containing spike } \\
\text { waves and slow rhythms }\end{array}$ \\
\hline
\end{tabular}

\section{AUXILIARY EXAMINATION}

Except for abnormal liver function, elevated serum bilirubin, separation of enzyme and bile (highly elevated serum bilirubin associated with liver enzymes reduced) and reduced prothrombin time activity, the examinations helpful to HE diagnosis are as following: blood ammonia

The fasting blood ammonia of normal people is $6-35 \mu \mathrm{g} / \mathrm{L}$ (serum) or $47-65 \mu \mathrm{g} / \mathrm{L}$ (whole blood). In patients with type-B and type-C HE, the blood ammonia rises, while in patients with type-A HE, the blood ammonia is often normal.

\section{Plasma amino acids imbalance}

Branched chain amino acids reduce and aromatic amino acids increase, resulting in the ratio of the two below 1 ( $>3$ in normal cases). But due to the requirment of special apparatus, no examination can be conducted at ordinary laboratory at present.

\section{Neuropsychological and intelligence detection}

It is significant to the diagnosis of MHE. At present, there are many methods for detection, but most of them are subject to age, gender and education level of the patients. Such methods are recommended as the Number Connection Test, part A (NCT-A, Appendix 4a-1) and part B (NCT-B, Appendix 4a-2); the LineTracing Test (LTT, Appendix 4b), the Brief Visuospatial
Memory Test-Revised (BVMT-R) (Appendix 5), the Clock Drawing Test (CDT, Appendix 6), ${ }^{6}$ the DigitSymbol Test (DST, Appendix 4d) and the Serial Dotting Test (Appendix 4c), etc. These methods feature small correlation with the level of education, very simple and convenient operation (Evaluating criterion of these tests is given in Appendix 4f). Mini-Mental State Examination (MMSE, Appendix 7) can well reflect the situation of slight neuropsychiatric damage which take too much time (a check takes 5 to 10 minutes). They all can be conducted in clinical trials.

\section{Neurophysiological tests \\ EEG}

Generally, neurophysiological abnormality can be detected by EEG before biochemical or mental abnormalities. The main manifestation is slow rhythms, which usually appears on both sides of the forehead and the top and then gradually moves backward. EEG changes are not specific for HE, which can be detected in other metabolic encephalopathies such as uremic encephalopathy, but the severity of these changes is highly related to the clinical stage.

\section{Evoked potentials (EPs)}

There are many kinds of EPs, but endogenous event related EPs P300 with more sensitivity, is a better choice for the diagnosis of HE. However, due to the limitations of instrument, equipment and professionals, it is only applied in clinical trails. 


\section{Critical flicker frequency (CFF)}

This method was originally applied for detection of the critical flicker frequency of warning disorders and can reflect the ability of central nervous system. In recent years, a compared study on 217 individuals (including cirrhosis patients and healthy population) in Spain showed that CFF can sensitively diagnose MHE (including minor $\mathrm{HE}$ and $\mathrm{HE}$ stage 1) and is reliable, simple, easy to apply. But as the application of CFF for diagnosis MHE is just on the start, further clinical application is required for its diagnostic value. ${ }^{7}$

\section{Imaging examination}

Cranial CT and MRI can detect cerebral edema. Manganese deposition can cause changes in structure of astrocytes. In examination of head MRI, frontal cortex brain atrophy and enhanced T1-weighted signal of globus pallidus and core-shell capsule can be detected. The main value of cranial CT and MRI is to exclude other causes of an abnormal mental state including cerebrovascular accident, intracranial tumor and other brain diseases.

\section{DIAGNOSIS AND DIFFERENTIAL DIAGNOSIS}

\section{Diagnosis basis}

Hepatic encephalopathy is a diagnosis of exclusion. Now, there are still no golden standards for HE diagnosis. As for HE diagnosis, considerations should be based on the following aspects.

a. Different types of HE may occur in diverse clinical situations. Type-A HE occurs in patients with acute liver failure but without history of chronic liver disease; Type-B HE occurs in patients with portosystemic venous shunting but without liver disease basis; Type-C HE occurs in patients with severe liver disease and spontaneous or iatrogenic portosystemic venous shunting, such as cirrhosis, liver cancer, intrahepatic portosystemic shunt (TIPS).

b. The patients may occur neuropsychiatric symptoms and signs, such as alteration of mood and personality, confusion and inappropriate behavioral, disorientation, alternate lethargy and excitement, hypermyotonia, positive of asterixis, ankle clonus and pathological reflex. In serious cases, such symptoms as lethargy, confusion and even coma may appear.

c. Although the patients have no neuropsychiatric symptoms and signs, but their learning, understanding, attention, emergency and operating capacities defects. Through neuropsychological and intelligence test, there are at least two abnormalities. CFF anomalies can be taken as an important reference.

d. Patients with precipitating factors of $\mathrm{HE}$ (type $\mathrm{C}$ and type B), such as gastrointestinal bleeding, abdominal paracentesis to remove fluid, diuretic therapy, excessive protein dietary, taking tranquilizers and infection. The once-occurrence of HE is of great help to diagnosis. Type-A HE patients generally have no provocative factors.

e. To exclude other metabolic encephalopathies (such as the encephalopathies caused by ketoacidosis, hypoglycemia and uremia), toxic encephalopathies and nervous system diseases (such as intracranial hemorrhage, intracranial infections, psychosis and sedative overdose).

The patients with the conditions described as a., c., d. and e. above can be diagnosed as SHE patients; those who with the conditions of b., c., d. and e. above can be diagnosed as MHE patients.

$\mathrm{HE}$ is divided into different stages according to the severity of neuropsychiatric symptoms. Also, it can be graded according to West-Haven Scale, Glasgow Coma Scale or HESA.

\section{Differential Diagnosis}

Before diagnosis, HE should be discriminated with the following diseases:

\section{Psychosis}

HE, with psychiatric symptoms such as personality changes or abnormal behavior as the outstanding manifestations, can be easily misdiagnosed as psychosis. So, when the patients with serious liver diseases or portosystemic venous shunting history occurs neurological and psychiatric disorders, HE should be considered.

\section{Other metabolic encephalopathies}

\section{Ketoacidosis}

These patients with a history of diabetes get ill usually caused by infection, emergency or overeating, alcoholism, etc. The manifestations include aggravated diabetes, loss of appetite, nausea, vomiting, abdominal pain, dizziness, headache, blurred consciousness and lethargy. The blood sugar is often greater than 16.7 $\mathrm{mmol} / \mathrm{L}(300 \mathrm{mg} / \mathrm{dl})$ with positive urine acetone bodies. Hypoglycemia

Hypoglycemia may cause coma, often accompanied by sympathetic excitement, dizziness, palpitation, cold sweats, etc. Blood glucose concentration is often less than $2.8 \mathrm{mmol} / \mathrm{L}$, and the symptoms may disappear after sugar supplement.

Renal encephalopathy

The manifestations also include mental retardation, delirium, hallucination, asterixis, lethargy and even coma, but these patients have a history of acute/ chronic kidney disease and the evidence of azotemia, with reducing endogenous creatinine clearance rate, increasing blood urea nitrogen and creatinine or organic damage of kidney. 
Pulmonary encephalopathy

The symptoms include headache, dizziness, memory loss, lack of energy and reduced ability. The more serious symptoms include drowsiness, lethargy, coma, positive asterixis and ankle clonus. However, the patients have a history of respiratory diseases, associated with hypoxia and carbon dioxide retention manifestation. The $\mathrm{PaO}_{2}$ reduces and $\mathrm{PaCO}_{2}$ increase in blood, carbon dioxide combining power rises and blood $\mathrm{pH}$ decreases.

\section{Neurological diseases}

\section{Intracranial hemorrhage and intracranial tumor}

These patients generally have nervous systemic positioning signs. The patients with intracranial hemorrhage may have a history of high blood pressure. Cranial CT or MRI can detect the focus.

\section{Intracranial infection}

The symptoms include fever and infection poisoning. It has meningeal irritation signs. Cerebrospinal fluid examination can be helpful to diagnosis.

\section{Reye syndrome}

This is a group of syndromes featuring the cerebral edema and liver dysfunction caused by fat visceral organ infiltration. Its prominent clinical manifestations include liver dysfunction and cerebral edema. High blood ammonia, low blood sugar, prolonged prothrombin time, elevated serum transaminases and low serum bilirubin often occur too. So, it is easily misdiagnosed as acute HE. But Reye syndrome often occurs on children catching upper respiratory tract infection and taking salicylates (aspirin). A large amount of fat droplets in liver cells are helpful to diagnosis.

\section{Toxic encephalopathy}

Drugs and toxins such as carbon monoxide, alcohol, heavy metals like mercury and manganese can cause toxic encephalopathy. A thorough understanding of medical history will be helpful to its identification. Alcoholic liver disease can also result in HE, so it needs to be distinguished with the encephalopathy caused by ebrietas from HE.

Diagnosis process of HE (Figure 1)

\section{TREATMENT PRINCIPLES AND MEASURES}

HE is a complex metabolic disorder caused by a combination of factors, so comprehensive measures should be taken in many aspects. Different treatment schemes should be designed according to clinical types, different provocative factors and the severity of disease. Early recognition and prompt appropriate treatment is the key to improve HE prognosis, so aggressive treatment is necessary when determining the existence of MHE.

\section{Identification and removal of provocative factors}

Type-C HE has a variety of provocative factors. Actively searching and immediate elimination may effectively inhibit the development of HE. For instance, esophageal variceal bleeding can induce the onset of HE. Active hemostasis, anemia correction and intestinal blood clearing are favorable for HE control; active infection control, correction of electrolyte disturbance, elimination of constipation and improvement of renal function are also the basic therapies to control HE.

\section{Treatment of MHE}

MHE patients mostly have no obvious symptoms and signs. But the patients may have weaker operating ability and sleep disorders. Treatment options: a. To adjust the diet structure and appropriately reduce protein intake (referring to enteral nutrition); $b$. Try nonabsorbable disaccharides such as lactulose or lactitol (referring to reducing intestinal $\mathrm{pH}$ and inhibiting the growth of intestinal bacteria); c. Patients with sleep disorder should not take benzodiazepine to avoid inducing clinical HE (C).

\section{Symptomatic and supportive treatment}

Patients with HE often lose appetite or in a coma and could not eat. So the active nutritional support is necessary.

\section{Enteral nutrition}

In the past, it was recognized that restricting protein diets may reduce intestinal ammonia production and prevent exacerbations of HE. However, recent research found that patients with cirrhosis often suffer from malnutrition. Although strict protein restriction can prevent elevated blood ammonia, it can further deteriorate the nutritional status of the patients and increase the risk of liver damage and death. Positive nitrogen balance is favorable for liver cell regeneration and the ammonia detoxification of muscle tissue. Recently, Cordoba et al conducted a clinical control study which randomized 30 patients with episodic HE to either low-protein diet group (protein intake rose from $0 \mathrm{~g} / \mathrm{d}$ to $12 \mathrm{~g} / \mathrm{d}$ on the third day and the figure doubled each three days till hitting $1.2 \mathrm{~g} / \mathrm{kg}$ per day on the last two days) or normal protein diet group (1.2 $\mathrm{g} / \mathrm{kg}$ per day). ${ }^{8}$ The results showed that there was no obvious difference in mental function improvement and the rate of protein synthesis between the two groups, but the protein catabolic rate of patients in the low-protein diet group is obviously higher during the 14-day observation period. ESPEN (European Society for Clinical Nutrition and Metabolism) Guidelines on Enteral Nutrition amended in 2006 suggests a patient with liver disease is supplied with $146-167 \mathrm{~kJ} / \mathrm{kg}$ 


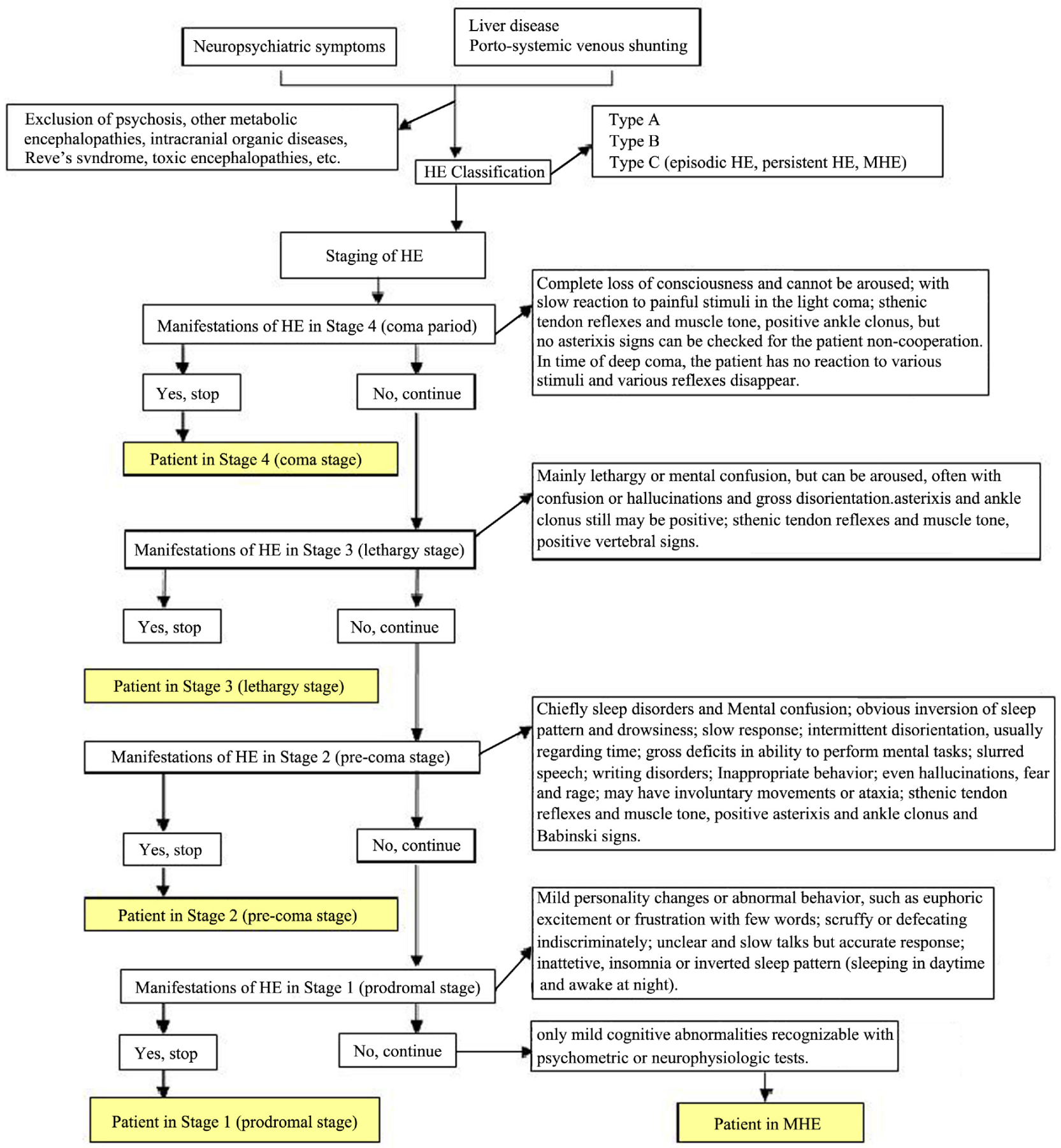

Figure 1. Diagnosis process of HE.

Notes: Other metabolic encephalopathies include ketoacidosis, hypoglycemic coma, renal encephalopathy, pulmonary encephalopathy, etc.; intracranial organic diseases include intracranial hemorrhage, intracranial tumor, intracranial infection, etc.; toxic encephalopathies include the encephalopathies caused by drugs, toxins, heavy metals and alcoholism.

$(35-40 \mathrm{kcal} / \mathrm{kg})$ of non-protein calories and a protein intake of $1.2-1.5 \mathrm{~g} / \mathrm{kg}$ per day. ${ }^{9}$

\section{Recommendations}

In patients with HE type-A or HE type-C in stage 3 or stage 4 , protein feeding can be withdrawn for the few beginning days $(\mathrm{C})$. After getting sober, the protein intake increases $10 \mathrm{~g}$ every 2-3 days gradually, aiming at $1.2 \mathrm{~g}$ protein $\cdot \mathrm{kg}^{-1} \cdot \mathrm{day}^{-1}$ (range $1-1.5 \mathrm{~g}$ ) (A); As for patients with HE type-C in stage 1 or stage 2, lowprotein diets $(20 \mathrm{~g} / \mathrm{d})$ should be provided in the few beginning days, then the amount will be increased every 2-3 days, also aiming at $1.2 \mathrm{~g}$ protein $\cdot \mathrm{kg}^{-1} \cdot \mathrm{day}^{-1}$ (range 1-1.5 g) if no HE occurs. Protein from vegetable and dairy sources are preferable to animal protein. In cases with vegetable protein, nonabsorbable fiber, less methionine and aromatic amino acids and more 
branched-chain amino acids should be provided. The fiber is a substrate for colonic bacteria and subsequent colonic acidification, a natural cathartic, which can increase the discharge of fecal nitrogen. Animal protein (with the strongest encephalopathy-inducing effect) should be avoided as much as possible. Oral intake or intravenous supplement of necessary amino acid and branched-chain amino acids is favorable for the adjustment of amino acid proportion, promoting positive nitrogen balance and increasing the patients tolerance to protein. Meanwhile, the patients should be given sufficient calories (146-167 kJ/kg, $35-40$ $\mathrm{kcal} / \mathrm{kg}$ per day), mainly from carbohydrate. If patients are not able to maintain adequate oral intake from normal food, tube feeding or intravenous nutritional supplements should be given.

\section{Zinc supplementation}

Zinc is an important cofactor of urea cycle enzyme. Zinc deficiency is common in cirrhosis, especially if associated with malnutrition. Zinc supplementation can improve the activity of urea cycle and also has the potential to reduce the absorption of divalent cations like manganese. But, so far, there is no consensus on the results of some clinical studies in validating the therapeutic effect of zinc on HE yet. ${ }^{11}$ Further clinical control study is still needed to explore its application value.

Water, electrolyte and acid-base balance

Hyponatremia, hypokalemia, hyperkalemia and alkalosis are all important precipitating factors to HE, and active corrections should be given according to the level of serum electrolytes and blood gas analysis results. The fluid volume of daily supplementation should be determined according to the urine volume of previous day (urine volume $+1000 \mathrm{ml}$ ) and the total volume should be controlled within $2,500 \mathrm{ml}$.

\section{Treatment of basic diseases}

Patients with hypoproteinemia may maintain colloid osmotic pressure by intravenous infusion of plasma and albumin. Albumin supplementation can also promote the repair of liver cells. As for patients with brain edema, alternate rapid infusion of $20 \%$ mannitol or $50 \%$ glucose should be adopted; moreover, adequate vitamin $\mathrm{B}$, vitamin $\mathrm{C}$, vitamin $\mathrm{K}$, ATP and co-enzyme A should be added to improve the energy metabolism of brain.

\section{Treatment targetting at the pathogenesis}

Reduction in the production and absorption of ammonia and other harmful substances from the intestinal tract

\section{Bowel cleansing}

Because the toxins responsible for HE chiefly arise from the gut, bowel cleansing is a mainstay of therapy. Colonic cleansing can reduces the luminal production and absorption of ammonia and other toxic substances, and could lower blood ammonia in cirrhotic patients. The retention of food, blood or other toxic substances in intestinal tract can be cleaned through catharsis or enema.

\section{Recommendations}

Twenty five percent magnesium sulfate $(30-60 \mathrm{ml}$, ingested or via nasogastric tube p.o.) could be given for catharsis. Irrigation with non-absorbable disaccharides solution (such as lactulose, $300-500 \mathrm{ml}$ in $500 \mathrm{ml}$ water) can also be taken for enema, especially suitable for HE with portosystemic venous shunting.

Reducing intestinal $\mathrm{pH}$ and inhibiting the growth of intestinal bacteria

Application of non-absorbable disaccharides (lactulose and lactitol) ${ }^{12}$

Lactulose is a kind of disaccharide. As there is no lactulose enzyme in the human digestive tract, it is not broken down by intestinal disaccharidases and not absorbed in the stomach and small intestine. Thus, it could reach the colon, where bacteria will metabolize the disaccharidases to acetic acid and lactic acid. This could lower the colonic $\mathrm{pH}$, inhibit intestinal ammonia production, and promote the conversion of lumenal ammonia $\left(\mathrm{NH}_{3}\right)$ to ammonium $\left(\mathrm{NH}_{4}{ }^{+}\right)$, which should be less readily absorbed into the bloodstream from the bowel lumen. The production of organic acids by bacterial fermentation can also increase bowel lumen osmotic pressure, with the acidification of the colon, underlies its cathartic effect, which is helpful for the discharge of ammonia and other toxic substances in intestinal tract. Non-absorbable disaccharides, as prebiotics, are hostile to the survival of ureaseproducing intestinal bacteria and reduce the production of ammonia in colon. Abdominal discomfort, flatulence, and abdominal cramping, anorexia, nausea, vomiting and diarrhea are the most frequent subjective complaints with this drug. The miscellaneous sugar content of non-absorbable disaccharides is low (2\%), so it is also applicable to patients with diabetic or lactase deficiency. However, they should be forbidden in patients with ileus. A number of randomized control studies showed that lactulose or lactitol can remarkably improve $\mathrm{HE}$ and the life quality of patients than placebo, but it still remains unknown whether it can improve the patients survival rate. ${ }^{12,13}$

\section{Recommendations}

For patients with acute encephalopathy, lactulose (ingested or via nasogastric tube, $45 \mathrm{ml} \mathrm{p.o.} \mathrm{)} \mathrm{is} \mathrm{given}$ every hour until evacuation occurs. ${ }^{2}$ Then the dose is adjusted to an objective of two to three soft bowel movements per day (generally $15-45 \mathrm{ml}$ every 8-12 hours) (A); Lactulose by enema (300 $\mathrm{ml}$ in $1 \mathrm{~L}$ water) is retained for 1 hour, with the patient in trendelenburg position (to increase the possibility of access to the 
right colon). For patients with chronic encephalopathy, oral lactulose does not require the hourly initial administration. Lactitol, the lactulose derivative, has the same mechanism of action and effect as lactulose. But it is more palatable and better tolerated. The usual dose is $0.5 \mathrm{~g} / \mathrm{kg}$, bid, which can be adjusted to an objective of two to three soft bowel movements per day (A).

\section{Application of probiotics}

The probiotics (including bifidobacterium and lactobacillus) can restrict the growth of ammoniaproducing and urease-producing intestinal bacteria by adjusting the structure of intestinal flora, resulting in reduced production and absorption of intestinal ammonia and other toxic substances. It can be applied together with prebiotics. In a recent open study, 190 patients with cirrhosis (55\% with MHE) were randomly divided into 3 groups to respectively receive lactulose $30-60 \mathrm{ml} / \mathrm{d}$ or probiotic capsule (a quadrigeminus active bacterial agent including lactobacillus and streptococcus faecalis, etc.) or receive both kinds of treatment. After 1 month treatment, the patients achieved obvious improvement on neuropsychological test, P300 auditory evoked potential and the ammonia level in blood, but there was no significant difference among the efficacy of three groups. ${ }^{14}$

\section{Recommendations}

Live combined bifidobacterium, lactobacillus and enterococcus capsules, 2-3 tablets/time, tid, p.o.; Bacillus licheniformis capsules, 2 tablets /time, tid (B). Application of antibiotics

Antibiotic is a therapeutic alternative to nonabsorbable disaccharides for treatment in acute and chronic HE.

In the past, it is recognized that oral intake of few-absorbable aminoglycoside antibiotics such as neomycin is beneficial to inhibit the overgrowth of colonic bacteria. However, the recent randomized placebo control study showed that neomycin is essentially contraindicated; it was found that a proportion of the ingested dose is indeed absorbed due to increased gut permeability, thus the risk of ototoxicity and renal toxicity and small intestine mucosa dysfunction may occur. Metronidazole can inhibit intestinal anaerobic bacteria and improve HE, but long-term use may result in the alteration of intestinal flora, gastrointestinal discomfort or neurotoxicity. ${ }^{15}$ Non-aminoglycoside antibiotics rifaximin is a derivative of rifampin and has a broadspectrum and strong restriction on the growth of bacteria in intestinal tract. It is non-absorbable and only locally works in the gastrointestinal tract. It showed that $550 \mathrm{mg}$ rifaximin in succession (bid), can remarkably prevent the occurrence of HE than placebo. ${ }^{16,17}$ In terms of chronic HE treatment, rifaximin has an effect equal to that of lactulose or neomycin and has no toxicity to the auditory nerve and renal function. ${ }^{17,18}$

Recommendations

Rifaximin 1,200 mg/d, tid (A).

The combination of antibiotics and non-absorbable disaccharides

Retrospective data analysis showed that the combination of two drugs can significantly lower the patients hospitalization rate and hospitalization time, but its potential therapeutic benefit remains to be further studied. ${ }^{19}$

Promote the metabolism of ammonia, antagonize false neurotransmitter and improve the balance of amino acids

Ammonia-lowering drugs

a. L-ornithine-L-aspartate (L-ornithine L-aspartate, LOLA, OA): OA is a stable salt of the 2 constituent amino acids. L-ornithine is the substrate of urea cycle (ornithine cycle). It can increase the activity of carbamoyl phosphate synthetase and ornithine carbamyl transferase and stimulates the synthesis of urea resulting in loss of blood ammonia. Both L-ornithine and L-aspartate are substrates for glutamate transaminase. With the administration of aspartate, ammonia is applied in the conversion of glutamate to glutamine and detoxification. Therefore, administration of OA can reduce the blood ammonia level. Aspartate is also involved in the synthesis of nucleic acids in the liver cells and indirectly promotes the metabolic process of Krebs cycle within the liver cells, thus facilitating the repair of stem cell. Clinical studies showed that compared with placebo control group, $20 \mathrm{~g} / \mathrm{d}$ OA intravenous infusion can significantly reduce fasting blood ammonia and postprandial blood ammonia and improvement in the mental state grade of HE patients. ${ }^{20}$ Oral administration of OA can improve the results of NCT-A, asterixis and EEG in patients with HE. ${ }^{21}$

\section{Recommendations}

For acute and chronic HE patients, OA (40 g) can be given within 24 hours. After patients getting sober, the dose of OA can be reduced to $20 \mathrm{~g} / \mathrm{d}$. For vein tolerability, the OA dose per $500 \mathrm{ml}$ of solution should not exceed $30 \mathrm{~g}$. The injection speed should not exceed $5 \mathrm{~g} / \mathrm{h}$. Thus such adverse reactions as nausea and vomiting could be avoided (A).

b. Arginine: As an intermediate metabolite ornithine cycle in the process of urea synthesis in liver, it can promote the synthesis of urea and lower blood ammonia. The clinical preparations are its hydrochloride salt. Being acidic, it can acidify blood and reduce the toxic effect of ammonia on the center.

Recommendations

Arginine hydrochloride $(25 \%, 40-80 \mathrm{ml}$ added to the glucose solution, i.v. q.d.) can be used (A). It can also correct alkalemia. 
c. Glutamate: As the substrate of glutamine synthesis, sodium glutamate and potassium glutamate can reduce blood ammonia and adjust the balance between potassium and sodium. However, it is believed in recent years that glutamate can only temporarily reduce ammonia, and could not penetrate blood-brain barrier and reduce the ammonia in brain tissue, and may induce metabolic alkalosis and aggravate HE. In addition, the hypertonic effect caused by the excessive glutamine in brain is involved in the formation of brain edema, which is unfavorable to the recovery of HE. Therefore, it is no longer recommended for HE treatment.

\section{The effect of antagonistic false neurotransmitters}

Endogenous benzodiazepine analogues binding to the $\gamma$-aminobutyric acid receptor complex has been proposed as an important factor in the pathogenesis of HE. Theoretically, it is feasible to use fumazenil, the antagonist of the receptor for HE treatment. A large clinical trial of 560 cases showed that the improvement rate of brain function in patients treated with fumazenil or placebo is $15 \%$ and $3 \%$, respectively. ${ }^{2}$ The other 12 controlled studies on 765 patients showed that fumazenil can significantly improve HE, but did not show long-term benefits or improve the survival rate of patients. Therefore, its application is only considered for the patients who recently received benzodiazepines. Alterations of dopaminergic neurotransmission were initially postulated to contribute to the pathogens of HE. However, clinical controlled trials showed that the application of bromocriptine and levodopa could not give other benefits to HE patients in addition to partially improving the extrapyramidal symptoms of HE patients.

\section{Recommendations}

a. Flumazenil ( $1 \mathrm{mg}$ bolus i.v.) is indicated for patients who recently received benzodiazepines (B).

b. Bromocriptine (30 mg p.o. b.i.d.) is indicated for patients with extrapyramidal symptoms and unresponsive to other therapies $(\mathrm{C})$.

Correction of the imbalance between aromatic and branched-chain amino acids

Oral administration or intravenous infusion of branched-chain amino acid can correct amino acid metabolic imbalance and inhibit the formation of false neurotransmitters in brain. A meta analysis on five trials showed that the intravenous infusion of branched-chain amino acids can significantly improve the symptoms of HE. Although two of the five trials and another trial failed to reduce the mortality of HE patients by branched-chain amino acids, ${ }^{3}$ two large-scale trials in recent years (randomized control trials on 174 and 622 patients with cirrhosis, respectively) showed that the application of branched-chain amino acids not only reduce the incidence of $\mathrm{HE}$, but also improve the nutritional status of patients, improve liver function, decrease the incidence of liver failure and improve the survival rate of HE. Other trials showed that branchedchain amino acids can also stimulate liver cells regeneration. Adequate intake of branched chain amino acid mixture is effective to restore the patients' positive nitrogen balance, increase patients tolerance to protein food and improve their cerebral blood perfusion. ${ }^{11}$ Its main side-effects include nausea, vomiting and allergic reactions, so the speed of infusion should be slow.

\section{Recommendations}

Branched chain amino acid mixture (250-500 ml q.d. i.v.) can be recommended (A).

\section{Treatment of underlying diseases}

Type A HE or type C HE occurs in patients with acute and chronic liver failure, respectively. Therefore, aggressive treatment of hepatic failure (referring to the Diagnostic and Treatment Guidelines for Liver Failure) is the fundamental prevention method to HE.

\section{Liver function improvement}

For chronic liver failure caused by viral hepatitis $\mathrm{B}$, antiviral treatment with nucleoside or nucleotide analogues is indicated, which is helpful to mitigate or eliminate liver inflammation, necrosis and promote regeneration, helpful to restore liver's metabolism and detoxification function. For acute liver failure, due to the rapid progress of the disease, it may be hard to work on antiviral therapy, and the patients need to be transferred to ICU for comprehensive treatment.

\section{Artificial liver support system}

The system can be divided into non-biological type, biological type and mixed type. But only non-biological type is widely used in current clinical treatment, including hemodialysis, hemofiltration, plasmapheresis, hemoperfusion and plasma adsorption. Artificial liver support system can replace some functions of the liver to clear the accumulation of poisons in the body and provide conditions and times for the regeneration of liver cells. It is a transition therapy for patients waiting for liver transplantation and can be used in acute or chronic HE. But, in case of acute liver failure or endstage liver disease, liver transplantation may be the only useful therapy.

\section{Liver transplantation}

For some severe HE, internal medicine therapy could not work well, then orthotopic liver transplantation may be the only effective treatment method.

\section{Blocking portosystemic venous shunting}

Theoretically, a permanency or temporary blocking of serious portosystemic venous shunting in patients with HE may be helpful to improving patients mental state. However, due to the existence of portal hypertension, the method could increase the risk of gastrointestinal bleeding, so it should be weighed thoroughly before 
carrying out.

\section{PREVENTION}

Let patients know the precipitating factors and avoid their occurrence as much as possible by public health education.

Arrange the diet reasonably. The patients who catch cirrhosis or once caught HE should avoid high-protein diet and high-dose diuretics.

Guide the family members of the patients to observe the personality and behavior changes of the patients and recommend the family members to use "Clinical Hepatic Encephalopathy Staging Scale (CHESS) (Appendix 8)" to check the patient for early detection and treatment.

(Drafted by Hui-chun Xing)

(Committee of experts: Xin-yue Chen, Jun Cheng, Fang-ling Duan, Jian-gao Fan, Xiao-ling Fan, Li-min Guo, Ming-zhou Guo, Tao Han, Jing-yuan Liu, Xiong Ma, Wei Shen, Shi-guang Feng, Xian-bo Wang, Yun Wu, Wen Xie, Yao Xie, Hui-chun Xing, Ping-geYuan, Yong-ping Yang and Fu-kui Zhang)

\section{REFERENCES}

1. Ferenci P, Lockwood A, Mullen K, Tarter R, Weissenborn K, Blei AT. Hepatic encephalopathy--definition, nomenclature, diagnosis, and quantification: final report of the working party at the 11th World Congresses of Gastroenterology, Vienna, 1998. Hepatology 2002;35:716-721.

2. Blei AT, Cordoba J. Hepatic Encephalopathy. Am J Gastroenterol 2001;96:1968-1976.

3. Riordan SM, Williams R. Treatment of hepatic encephalopathy. $\mathrm{N}$ Engl J Med 1997;337:473-479.

4. Zhu CW, Zhu WN. Hepatic encephalopathy. Practice of internal medicine. Beijing:People Medical Press. 2007;2026-2033.

5. Hassanein TI, Hilsabeck RC, Perry W. Introduction to the Hepatic Encephalopathy Scoring Algorithm (HESA). Dig Dis Sci 2008;53:529-538.

6. Fu YZ, Xie JW. The application of clock drawing test and MMSE in diagnosis of minimal hepatic encephalopathy. J Clin Res 2007;8:1280-1282.

7. Romero-Gomez M, Cordoba J, Jover R, del Olmo JA, Ramirez M, Rey R, et al. Value of the critical flicker frequency in patients with minimal hepatic encephalopathy. Hepatology 2007;45:879-885.
8. Cordoba J, Lopez-Hellin J, Planas M, Sabin P, Sanpedro F, Castro F, et al. Normal protein diet for episodic hepatic encephalopathy: results of a randomized study. J Hepatol 2004;41:38-43.

9. Plauth M, Cabre E, Riggio O, Assis-Camilo M, Pirlich M, Kondrup J, et al. ESPEN Guidelines on Enteral Nutrition: Liver disease. Clin Nutr 2006;25:285-294.

10. Shi H, Liu HY. Diagnosis of hepatic encephalopathy. Jia L, Li ZS. Chief editors. Hepatic Encephalopathy, Beijing, People's Military Medical press.2007:94-105.

11. Morgan MY, Blei A, Grungreiff K, Jalan R, Kircheis G, Marchesini G, et al. The treatment of hepatic encephalopathy. Metab Brain Dis 2007;22:389-405.

12. Prasad S, Dhiman RK, Duseja A, Chawla YK, Sharma A, Agarwal R. Lactulose improves cognitive functions and health-related quality of life in patients with cirrhosis who have minimal hepatic encephalopathy. Hepatology 2007;45:549-559.

13. Als-Nielsen B, Gluud LL, Gluud C. Nonabsorbable disaccharides for hepatic encephalopathy. Cochrane Database Syst Rev 2004;2:CD003044.

14. Sharma P, Sharma BC, Puri V, Sarin SK. An open-label randomized controlled trial of lactulose and probiotics in the treatment of minimal hepatic encephalopathy. Eur J Gastroenterol Hepatol 2008;20:506-511.

15. Al Sibae MR, McGuire BM. Current trends in the treatment of hepatic encephalopathy. Ther Clin Risk Manag 2009;5:617-626.

16. Bass N, Mullen K, Sigal S, Sanyal A, Poordad F, Merchant K, et al. Rifaximin is effective in maintaining remission in hepatic encephalopathy: Results of a large, randomized, placebocontrolled trial. J Hepatol 2009;50 (Suppl 1):S53.

17. Mas A, Rodes J, Sunyer L, Rodrigo L, Planas R, Vargas V, et al. Comparison of rifaximin and lactitol in the treatment of acute hepatic encephalopathy: results of a randomized, double-blind, double-dummy, controlled clinical trial. J Hepatol 2003;38:51-58.

18. Jiang Q, Jiang XH, Zheng MH, Jiang LM, Chen YP, Wang L. Rifaximin versus nonabsorbable disaccharides in the management of hepatic encephalopathy: a meta-analysis. Eur J Gastroenterol Hepatol 2008;20:1064-1070.

19. Mantry PS, Munsaf S. Does the addition of rifaximin to lactulose reduce the severity of hepatic encephalopathy? A single-center experience [abstract]. Hepatology 2008;48:517A, \#472.

20. Ahmad I, Khan AA, Alam A, Dilshad A, Butt AK, Shafqat $F$, et al. L-ornithine-L-aspartate infusion efficacy in hepatic encephalopathy. J Coll Physicians Surg Pak 2008;18:684-687.

21. Poo JL, Gongora J, Sanchez-Avila F, Aguilar-Castillo S, GarciaRamos G, Fernandez-Zertuche M, et al. Efficacy of oral L-ornithine-L-aspartate in cirrhotic patients with hyperammonemic hepatic encephalopathy. Results of a randomized, lactulosecontrolled study. Ann Hepatol 2006;5:281-288. 


\section{Appendix 1. West-Haven Scale ${ }^{1}$}

\begin{tabular}{ll}
\hline Grades & Distinguishing features \\
\hline \multirow{2}{*}{ Grade 1} & Trivial lack of awareness \\
& Euphoria or anxiety \\
& Shortened attention span \\
& Impairment of addition \\
Grade 2 & Lethargy or apathy \\
& Minimal disorientation for time and place \\
& Subtle personality change \\
& Inappropriate behavior \\
Grade 3 & Impairment of subtraction \\
& Somnolence to semi-stupor, but responsive to verbal stimuli \\
Grade 4 & Confusion \\
\hline
\end{tabular}

\section{Appendix 2. Glasgow Coma Scale ${ }^{2}$}

\begin{tabular}{lllll}
\hline Eyes open & & Best motor responses & \multicolumn{2}{c}{ Best verbal responses } \\
\hline Spontaneously & 4 & Obeys verbal orders & 6 & Oriented, conversant \\
To command & 3 & Localizes painful stimuli & 5 & Disoriented, conversant \\
To pain & 2 & Painful stimulus, flexion & 3 & Inappropriate words \\
No response & 1 & Painful stimulus, extension & 2 & Inappropriate sounds \\
& & No response & 1 & No response \\
\hline
\end{tabular}

Notes: To obtain the score, the best ocular, verbal and motor responses are summed. The best score is 15 and the worst 3 . Severe encephalopathy is defined as a score under 12 .

\section{Appendix 3. Hepatic Encephalopathy Scoring Algorithm (HESA) ${ }^{3}$}

\begin{tabular}{|c|c|}
\hline Grade 4 & $\begin{array}{l}\circ \text { No eyes opening } \\
\circ \text { No verbal/voice response } \\
\circ \text { No reaction to simple commands }\end{array}$ \\
\hline \multicolumn{2}{|c|}{ All applicable $=$ Grade 4 Otherwise continue examination } \\
\hline Grade 3 & $\begin{array}{l}\circ \text { Somnolence } \\
\circ \text { Confusion } \\
\text { oDisoriented to place } \\
\circ \text { Bizarre Bchavior/Anger/Rage } \\
\circ \text { Clonus/Rigidity/Nysatgmus/Babinsky } \\
\square \text { Mental Control =0 }\end{array}$ \\
\hline \multicolumn{2}{|c|}{3 or more applicable $=$ Grade 3 Otherwise continue examination } \\
\hline Grade 2 & $\begin{array}{l}\circ \text { Lethargy } \\
\circ \text { Loss of time } \\
\circ \text { Slurred speech } \\
\circ \text { Hyperactive reflexes } \\
\circ \text { Imappropriate Bchavior } \\
\square \text { Slow response } \\
\square \text { Amnesia of recent events } \\
\square \text { Anxiety } \\
\square \text { Impaired simple computations }\end{array}$ \\
\hline \multicolumn{2}{|c|}{2 or more $\circ$ and 3 or more $\square$ applicable $=$ Grade 2 Otherwise continue } \\
\hline Grade 1 & $\begin{array}{l}\circ \text { Sleep disorder/impaired sleep pattern } \\
\circ \text { Tremor } \\
\square \text { Impaired complex computations } \\
\square \text { Shortened attention span } \\
\square \text { Impaired construction ability } \\
\square \text { Euphoria or depression }\end{array}$ \\
\hline 40 & applicable $=$ Grade 1 Otherwise Grade 0 \\
\hline
\end{tabular}

Notes: $\circ$ indicates symptoms assessed using clinical judgment and $\square$ indicates symptoms assessed using neuropsychological measures. 


\section{Appendix 4a. NCT-A, B}

Number connection test (NCT) is divided into part A (NCT-A) and part B (NCT-B).

NCT-A: Connect the 1 arbitrarily ordered figures together according to the numbers order. NCT-B: Connect the integers from 1 to 13 and the English letters from A to L according to 1-A, 2-B order, etc. In case that mistake is made in the process of connection, immediate correction should be made and the connection should continue from the correction point.

Record the spent time, including the time to correct mistakes.

NCT-A is widely applied, and NCT-B is being abandoned as it is subject to educational and cultural level and has low specificity in China. (Referring to evaluating criterion of $4 \mathrm{a} 1,4 \mathrm{a} 2$ )
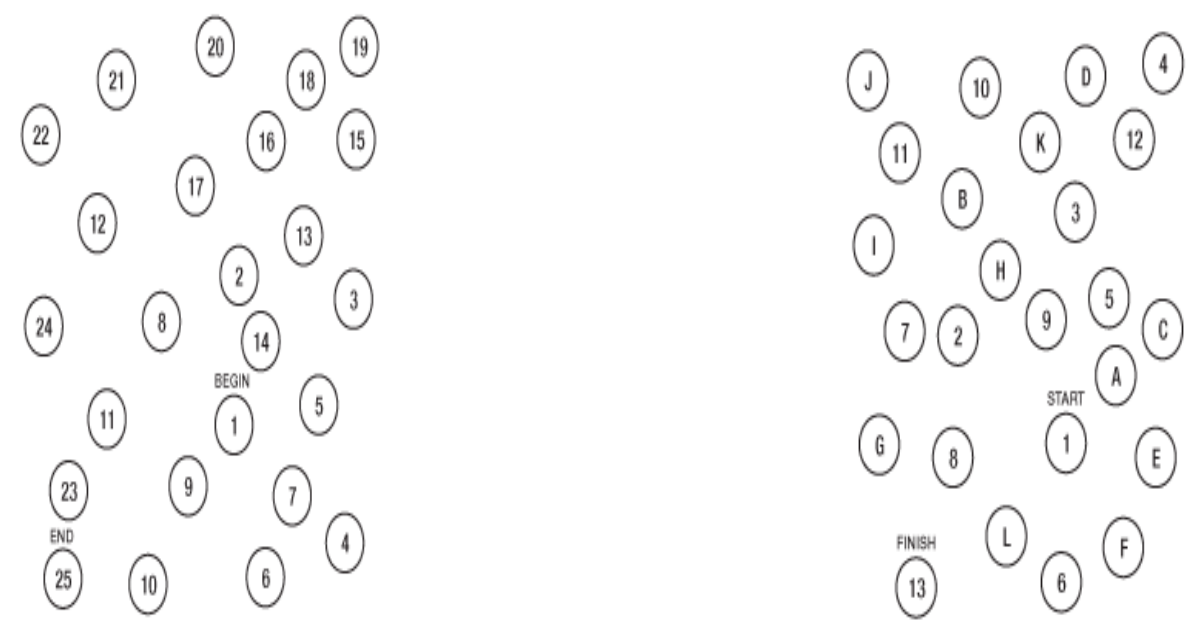

\section{Appendix 4b. Line-tracing test (LTT)}

Draw a line along the track established with the other two lines. The line could not be drawn cross or exposure to the track's lines. During the operation, the paper could not be moved and the pen could not leave the paper, and errors could be reduced as much as possible. The total time spent on it and accumulated score (1 point is deducted if the tracing line boundary connected but not crossed them; 2 points are deducted if the tracing line crossed the boundary line but not connected the paper edges; 3 points is deducted if the tracing line crossed over the edges of the paper. Besides, the number of total error could be calculated) could be evaluated. (Referring to evaluating criterion of $4 \mathrm{~b} 1,4 \mathrm{~b} 2$ )

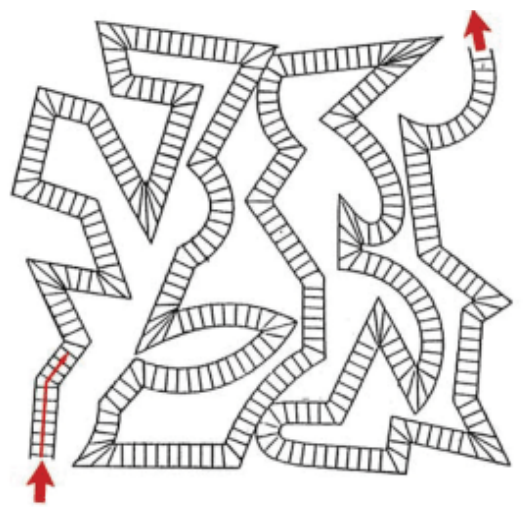




\section{Appendix 4c. Serial dotting test}

Draw a dot in the serial circle below respectively. The dot should be drawn near the center of each circle as much as possible. Two times exercises should be done before formal operation. (Referring to evaluating criterion of $4 \mathrm{c}$ )

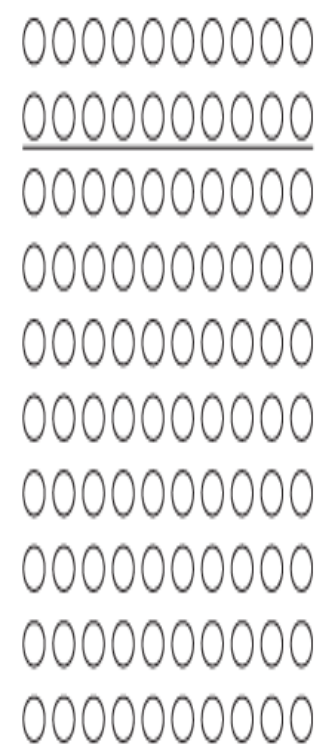

\section{Appendix 4d. Digit-symbol test (DST)}

Write the related symbol under each number according the example below. Record the spent time. (Referring to evaluating criterion of $4 \mathrm{~d}$ )

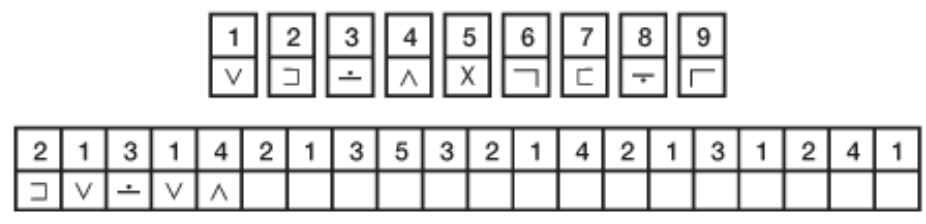

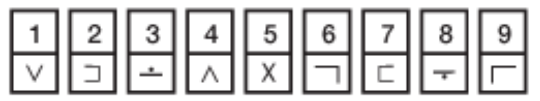

\begin{tabular}{|l|l|l|l|l|l|l|l|l|l|l|l|l|l|l|l|l|l|l|l|}
\hline 2 & 1 & 3 & 1 & 2 & 1 & 3 & 1 & 4 & 2 & 4 & 2 & 5 & 1 & 4 & 3 & 5 & 2 & 6 & 2 \\
\hline & & & & & & & & & & & & & & & & & & & \\
\hline
\end{tabular}

\begin{tabular}{|l|l|l|l|l|l|l|l|l|l|l|l|l|l|l|l|l|l|l|l|}
\hline 1 & 6 & 5 & 2 & 4 & 7 & 3 & 5 & 1 & 7 & 6 & 3 & 8 & 5 & 3 & 6 & 4 & 2 & 1 & 8 \\
\hline & & & & & & & & & & & & & & & & & & & \\
\hline
\end{tabular}

\begin{tabular}{|l|l|l|l|l|l|l|l|l|l|l|l|l|l|l|l|l|l|l|l|}
\hline 9 & 2 & 7 & 6 & 3 & 5 & 8 & 3 & 6 & 5 & 4 & 9 & 7 & 1 & 8 & 5 & 3 & 6 & 8 & 2 \\
\hline
\end{tabular}

\begin{tabular}{|l|l|l|l|l|l|l|l|l|l|l|l|l|l|l|l|l|l|l|l|}
\hline 7 & 1 & 9 & 3 & 8 & 2 & 5 & 7 & 4 & 1 & 6 & 7 & 4 & 5 & 8 & 2 & 9 & 6 & 4 & 3 \\
\hline & & & & & & & & & & & & & & & & & & & \\
\hline
\end{tabular} 
4a-1 NCT-A (Number connection test A)

ZVA

\begin{tabular}{|c|c|c|c|c|c|}
\hline & & 0WP & & & $-3 W P$ \\
\hline Alter (Jahre) & $+1 \mathrm{SD}$ & Norm & $-1 \mathrm{SD}$ & $-3 \mathrm{SD}$ & \\
\hline 14 & 14 & 19 & 26 & 44 & \\
\hline 15 & 14 & 19 & 26 & 45 & \\
\hline 16 & 14 & 20 & 27 & 46 & \\
\hline 17 & 15 & 20 & 27 & 47 & \\
\hline 18 & 15 & 20 & 27 & 47 & \\
\hline 19 & 15 & 21 & 28 & 48 & \\
\hline 20 & 16 & 21 & 28 & 49 & \\
\hline 21 & 16 & 21 & 29 & 50 & \\
\hline 22 & 16 & 22 & 29 & 51 & \\
\hline 23 & 16 & 22 & 30 & 51 & \\
\hline 24 & 17 & 23 & 30 & 52 & \\
\hline 25 & 17 & 23 & 31 & 53 & \\
\hline 26 & 17 & 23 & 31 & 54 & \\
\hline 27 & 17 & 24 & 32 & 55 & \\
\hline 28 & 18 & 24 & 32 & 56 & \\
\hline 29 & 18 & 25 & 33 & 57 & \\
\hline 30 & 18 & 25 & 33 & 58 & \\
\hline 31 & 19 & 25 & 34 & 59 & \\
\hline 32 & 19 & 26 & 35 & 60 & \\
\hline 33 & 19 & 26 & 35 & 61 & \\
\hline 34 & 20 & 27 & 36 & 62 & \\
\hline 35 & 20 & 27 & 36 & 63 & \\
\hline 36 & 20 & 28 & 37 & 64 & \\
\hline 37 & 21 & 28 & 37 & 65 & \\
\hline 38 & 21 & 29 & 38 & 66 & \\
\hline 39 & 21 & 29 & 39 & 67 & \\
\hline 40 & 22 & 29 & 39 & 68 & \\
\hline 41 & 22 & 30 & 40 & 69 & \\
\hline 42 & 23 & 30 & 41 & 70 & \\
\hline 43 & 23 & 31 & 41 & 72 & \\
\hline 44 & 23 & 32 & 42 & 73 & \\
\hline 45 & 24 & 32 & 43 & 74 & \\
\hline 46 & 24 & 33 & 43 & 75 & \\
\hline 47 & 25 & 33 & 44 & 77 & \\
\hline 48 & 25 & 34 & 45 & 78 & \\
\hline 49 & 25 & 34 & 46 & 79 & \\
\hline 50 & 26 & 35 & 46 & 80 & \\
\hline 51 & 26 & 35 & 47 & 82 & \\
\hline 52 & 27 & 36 & 48 & 83 & \\
\hline 53 & 27 & 37 & 49 & 85 & \\
\hline 54 & 28 & 37 & 50 & 86 & \\
\hline 55 & 28 & 38 & 50 & 87 & \\
\hline 56 & 29 & 39 & 51 & 89 & \\
\hline 57 & 29 & 39 & 52 & 90 & \\
\hline 58 & 30 & 40 & 53 & 92 & \\
\hline 59 & 30 & 40 & 54 & 93 & \\
\hline 60 & 31 & 41 & 55 & 95 & \\
\hline 61 & 31 & 42 & 56 & 97 & \\
\hline 62 & 32 & 43 & 57 & 98 & \\
\hline 63 & 32 & 43 & 58 & 100 & \\
\hline 64 & 33 & 44 & 59 & 102 & \\
\hline 65 & 33 & 45 & 60 & 103 & \\
\hline 66 & 34 & 46 & 61 & 105 & \\
\hline 67 & 35 & 46 & 62 & 107 & \\
\hline 68 & 35 & 47 & 63 & 109 & \\
\hline 69 & 36 & 48 & 64 & 110 & \\
\hline 70 & 36 & 49 & 65 & 112 & \\
\hline 71 & 37 & 49 & 66 & 114 & \\
\hline 72 & 38 & 50 & 67 & 116 & \\
\hline 73 & 38 & 51 & 68 & 118 & \\
\hline 74 & 39 & 52 & 69 & 120 & \\
\hline
\end{tabular}


To be continued

ZVA

\begin{tabular}{ccccccc} 
& \multicolumn{2}{c}{ 0WP } & & -1 WP & -2 WP & -3 WP \\
\hline Alter (Jahre) & +1 SD & Norm & -1 SD & -2 SD & -3 SD \\
\hline 75 & 40 & 53 & 70 & 93 & 122 \\
76 & 40 & 54 & 71 & 94 & 124 \\
77 & 41 & 55 & 73 & 96 & 126 \\
78 & 42 & 56 & 74 & 97 & 128 \\
79 & 42 & 57 & 75 & 99 & 130 \\
80 & 43 & 57 & 76 & 101 & 133 \\
\hline
\end{tabular}

4a-2. Number connection test B， NCT- B

ZVB
+1WP
OWP
$-1 \mathrm{WP}$
$-2 W P$
$-3 W P$

\begin{tabular}{|c|c|c|c|c|c|}
\hline Alter (Jahre) & $+1 \mathrm{SD}$ & Norm & $-1 \mathrm{SD}$ & $-2 \mathrm{SD}$ & $-3 \mathrm{SD}$ \\
\hline 14 & 33 & 45 & 60 & 80 & 106 \\
\hline 15 & 34 & 46 & 61 & 82 & 108 \\
\hline 16 & 35 & 47 & 63 & 83 & 110 \\
\hline 17 & 35 & 48 & 64 & 85 & 112 \\
\hline 18 & 36 & 48 & 65 & 86 & 115 \\
\hline 19 & 37 & 49 & 66 & 88 & 117 \\
\hline 20 & 37 & 50 & 67 & 89 & 119 \\
\hline 21 & 38 & 51 & 69 & 91 & 121 \\
\hline 22 & 39 & 52 & 70 & 93 & 123 \\
\hline 23 & 39 & 53 & 71 & 94 & 125 \\
\hline 24 & 40 & 54 & 72 & 96 & 128 \\
\hline 25 & 41 & 55 & 74 & 98 & 130 \\
\hline 26 & 42 & 56 & 75 & 100 & 133 \\
\hline 27 & 42 & 57 & 76 & 102 & 135 \\
\hline 28 & 43 & 58 & 78 & 103 & 137 \\
\hline 29 & 44 & 59 & 79 & 105 & 140 \\
\hline 30 & 45 & 60 & 81 & 107 & 143 \\
\hline 31 & 46 & 61 & 82 & 109 & 145 \\
\hline 32 & 47 & 63 & 84 & 111 & 148 \\
\hline 33 & 47 & 64 & 85 & 113 & 151 \\
\hline 34 & 48 & 65 & 87 & 115 & 153 \\
\hline 35 & 49 & 66 & 88 & 117 & 156 \\
\hline 36 & 50 & 67 & 90 & 120 & 159 \\
\hline 37 & 51 & 69 & 92 & 122 & 162 \\
\hline 38 & 52 & 70 & 93 & 124 & 165 \\
\hline 39 & 53 & 71 & 95 & 126 & 168 \\
\hline 40 & 54 & 72 & 97 & 129 & 171 \\
\hline 41 & 55 & 74 & 99 & 131 & 174 \\
\hline 42 & 56 & 75 & 100 & 133 & 177 \\
\hline 43 & 57 & 76 & 102 & 136 & 181 \\
\hline 44 & 58 & 78 & 104 & 138 & 184 \\
\hline 45 & 59 & 79 & 106 & 141 & 188 \\
\hline 46 & 60 & 81 & 108 & 144 & 191 \\
\hline 47 & 61 & 82 & 110 & 146 & 194 \\
\hline 48 & $\begin{array}{l}62 \\
64\end{array}$ & $\begin{array}{l}84 \\
85\end{array}$ & $\begin{array}{l}112 \\
114\end{array}$ & $\begin{array}{l}149 \\
152\end{array}$ & $\begin{array}{l}198 \\
202\end{array}$ \\
\hline $\begin{array}{l}49 \\
50\end{array}$ & $\begin{array}{l}64 \\
65\end{array}$ & $\begin{array}{l}85 \\
87\end{array}$ & $\begin{array}{l}114 \\
116\end{array}$ & $\begin{array}{l}152 \\
154\end{array}$ & $\begin{array}{l}202 \\
205\end{array}$ \\
\hline 51 & 66 & 89 & 118 & 157 & 209 \\
\hline 52 & 67 & 90 & 121 & 160 & 213 \\
\hline 53 & 69 & 92 & 123 & 163 & 217 \\
\hline 54 & 70 & 94 & 125 & 166 & 221 \\
\hline
\end{tabular}


To be continued

ZVB

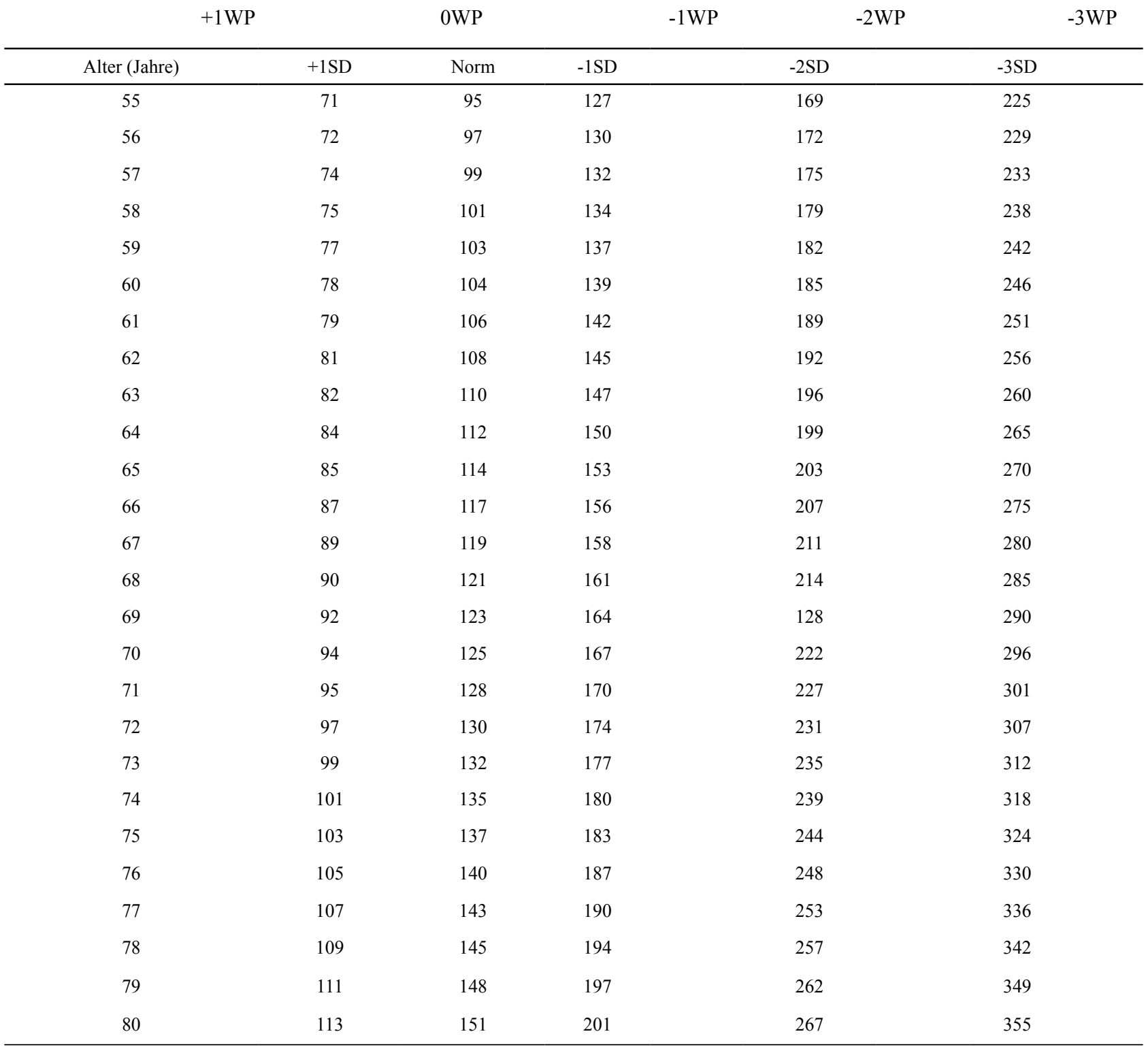

4b-1. Line-tracing test, LTT (time, s)

LNZ

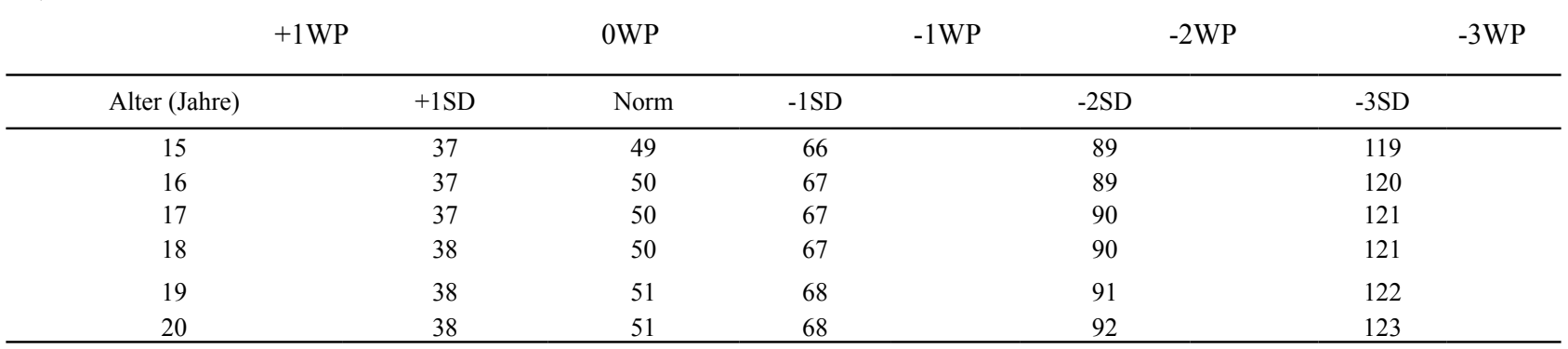


LNZ

To be continued

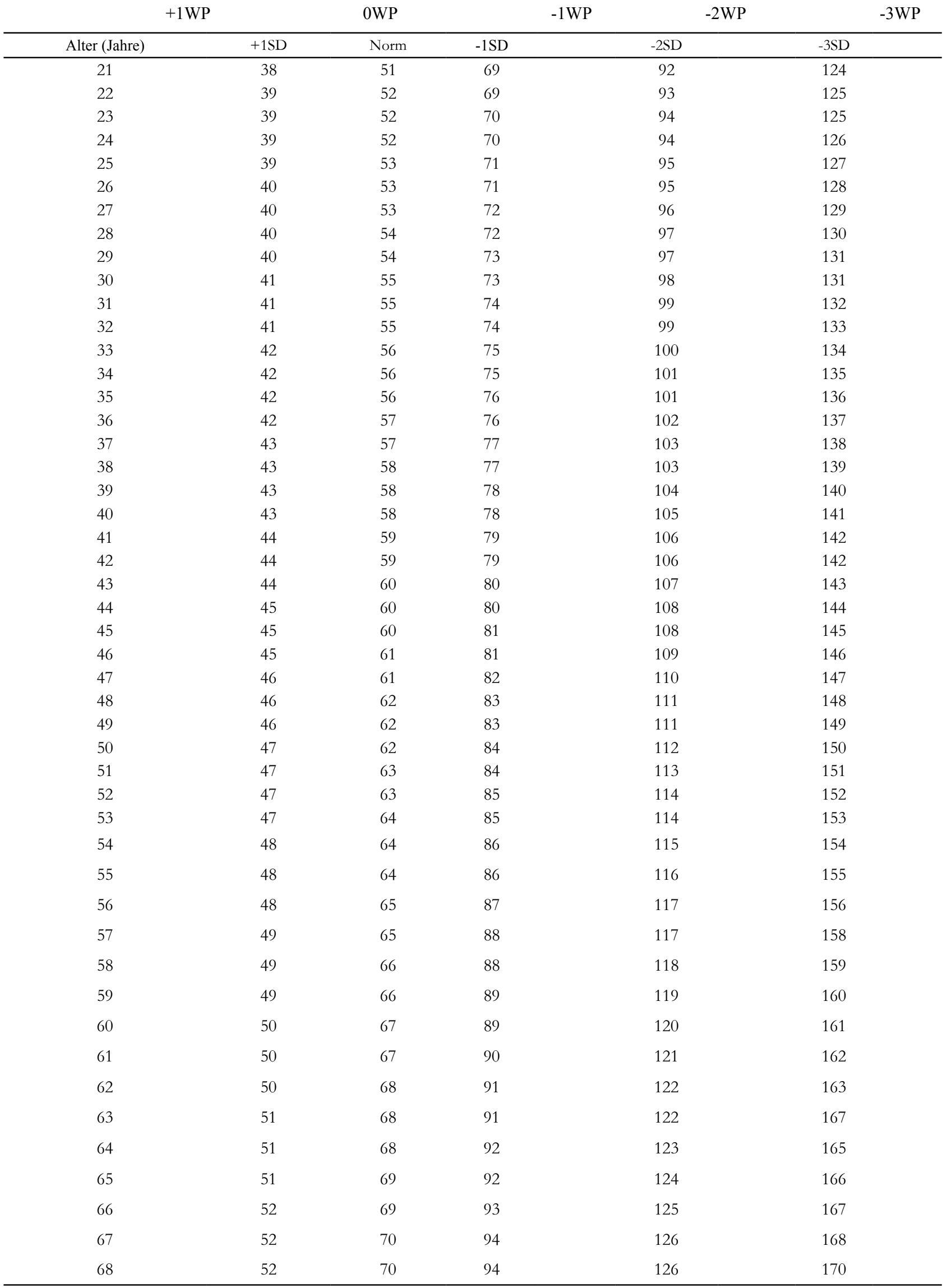


LNZ

To be continued

\begin{tabular}{|c|c|c|c|c|c|}
\hline Alter (Jahre) & $+1 \mathrm{SD}$ & Norm & $-1 \mathrm{SD}$ & $-2 \mathrm{SD}$ & $-3 \mathrm{SD}$ \\
\hline 69 & 53 & 71 & 95 & 127 & 171 \\
\hline 70 & 53 & 71 & 96 & 128 & 172 \\
\hline 71 & 54 & 72 & 96 & 129 & 173 \\
\hline 72 & 54 & 72 & 97 & 130 & 174 \\
\hline 73 & 54 & 73 & 98 & 131 & 175 \\
\hline 74 & 55 & 73 & 98 & 132 & 177 \\
\hline 75 & 55 & 74 & 99 & 133 & 178 \\
\hline 76 & 55 & 74 & 100 & 133 & 179 \\
\hline 77 & 56 & 75 & 100 & 134 & 180 \\
\hline 78 & 56 & 75 & 101 & 135 & 181 \\
\hline 79 & 56 & 76 & 102 & 136 & 183 \\
\hline 80 & 57 & 76 & 102 & 137 & 184 \\
\hline
\end{tabular}

\section{4b-2. Line-tracing test, LTT (accumulating error score)}

LNF

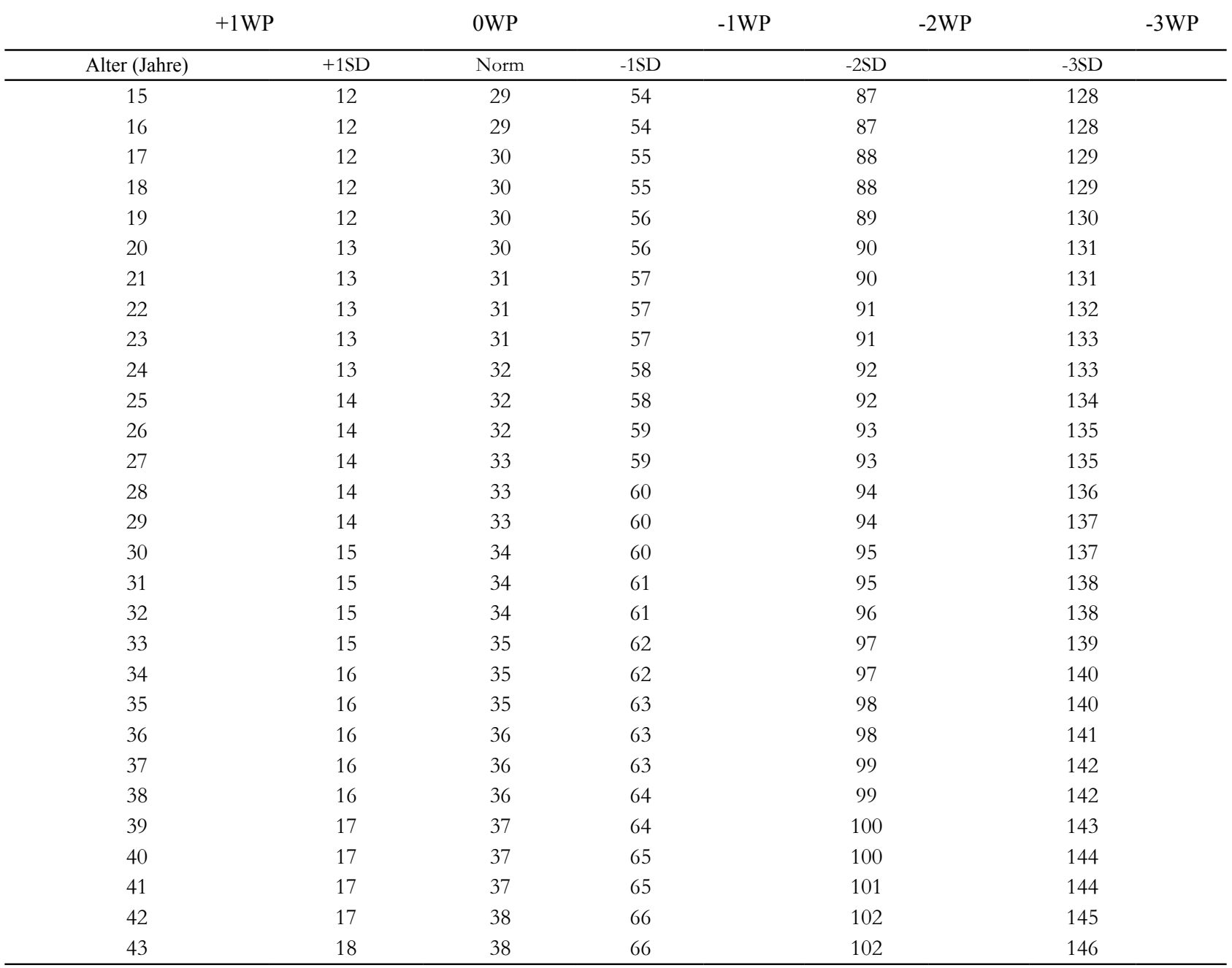


LNF

To be continued

\begin{tabular}{|c|c|c|c|c|c|}
\hline & & 0WP & & & \\
\hline Alter (Jahre) & $+1 \mathrm{SD}$ & Norm & $-1 \mathrm{SD}$ & $-2 \mathrm{SD}$ & $-3 S \mathrm{D}$ \\
\hline 44 & 18 & 38 & 67 & 103 & 147 \\
\hline 45 & 18 & 39 & 67 & 103 & 147 \\
\hline 46 & 18 & 39 & 68 & 104 & 148 \\
\hline 47 & 19 & 39 & 68 & 104 & 149 \\
\hline 48 & 19 & 40 & 68 & 105 & 149 \\
\hline 49 & 19 & 40 & 69 & 106 & 150 \\
\hline 50 & 19 & 40 & 69 & 106 & 151 \\
\hline 51 & 20 & 41 & 70 & 107 & 151 \\
\hline 52 & 20 & 41 & 70 & 107 & 152 \\
\hline 53 & 20 & 42 & 71 & 108 & 153 \\
\hline 54 & 20 & 42 & 71 & 108 & 153 \\
\hline 55 & 21 & 42 & 72 & 109 & 154 \\
\hline 56 & 21 & 43 & 72 & 110 & 155 \\
\hline 57 & 21 & 43 & 73 & 110 & 155 \\
\hline 58 & 21 & 43 & 73 & 111 & 156 \\
\hline 59 & 22 & 44 & 74 & 111 & 157 \\
\hline 60 & 22 & 44 & 74 & 112 & 158 \\
\hline 61 & 22 & 44 & 75 & 113 & 158 \\
\hline 62 & 22 & 45 & 75 & 113 & 159 \\
\hline 63 & 23 & 45 & 76 & 114 & 160 \\
\hline 64 & 23 & 46 & 76 & 114 & 160 \\
\hline 65 & 23 & 46 & 77 & 115 & 161 \\
\hline 66 & 23 & 46 & 77 & 116 & 162 \\
\hline 67 & 24 & 47 & 78 & 116 & 163 \\
\hline 68 & 24 & 47 & 78 & 117 & 163 \\
\hline 69 & 24 & 48 & 79 & 117 & 164 \\
\hline 70 & 25 & 48 & 79 & 118 & 165 \\
\hline 71 & 25 & 48 & 80 & 119 & 165 \\
\hline 72 & 25 & 49 & 80 & 119 & 166 \\
\hline 73 & 25 & 49 & 81 & 120 & 167 \\
\hline 74 & 26 & 49 & 81 & 120 & 168 \\
\hline 75 & 26 & 50 & 82 & 121 & 168 \\
\hline 76 & 26 & 50 & 82 & 122 & 169 \\
\hline 77 & 27 & 51 & 83 & 122 & 170 \\
\hline 78 & 27 & 51 & 83 & 123 & 170 \\
\hline 79 & 27 & 51 & 84 & 124 & 171 \\
\hline 80 & 27 & 52 & 84 & 124 & 172 \\
\hline
\end{tabular}




\section{4c. Serial dotting test, SDT}

KP

$+1 \mathrm{WP}$

0WP

$-1 \mathrm{WP}$

$-2 W P$

$-3 W P$

\begin{tabular}{|c|c|c|c|c|c|}
\hline Alter (Jahre) & $+1 \mathrm{SD}$ & Norm & $-1 \mathrm{SD}$ & $-2 S D$ & $-3 S D$ \\
\hline 15 & 31 & 36 & 43 & 50 & 59 \\
\hline 16 & 31 & 36 & 43 & 50 & 59 \\
\hline 17 & 31 & 37 & 43 & 51 & 59 \\
\hline 18 & 31 & 37 & 43 & 51 & 60 \\
\hline 19 & 32 & 37 & 43 & 51 & 60 \\
\hline 20 & 32 & 37 & 44 & 51 & 60 \\
\hline 21 & 32 & 37 & 44 & 52 & 61 \\
\hline 22 & 32 & 38 & 44 & 52 & 61 \\
\hline 23 & 32 & 38 & 44 & 52 & 61 \\
\hline 24 & 32 & 38 & 45 & 52 & 61 \\
\hline 25 & 32 & 38 & 45 & 53 & 62 \\
\hline 26 & 33 & 38 & 45 & 53 & 62 \\
\hline 27 & 33 & 38 & 45 & 53 & 62 \\
\hline 28 & 33 & 39 & 45 & 53 & 63 \\
\hline 29 & 33 & 39 & 46 & 54 & 63 \\
\hline 30 & 33 & 39 & 46 & 54 & 63 \\
\hline 31 & 33 & 39 & 46 & 54 & 64 \\
\hline 32 & 33 & 39 & 46 & 54 & 64 \\
\hline 33 & 34 & 40 & 46 & 55 & 64 \\
\hline 34 & 34 & 40 & 47 & 55 & 64 \\
\hline 35 & 34 & 40 & 47 & 55 & 65 \\
\hline 36 & 34 & 40 & 47 & 55 & 65 \\
\hline 37 & 34 & 40 & 47 & 56 & 65 \\
\hline 38 & 34 & 40 & 48 & 56 & 66 \\
\hline 39 & 35 & 41 & 48 & 56 & 66 \\
\hline 40 & 35 & 41 & 48 & 56 & 66 \\
\hline 41 & 35 & 41 & 48 & 57 & 67 \\
\hline 42 & 35 & 41 & 48 & 57 & 67 \\
\hline 43 & 35 & 42 & 49 & 57 & 67 \\
\hline 44 & 35 & 42 & 49 & 57 & 68 \\
\hline 45 & 36 & 42 & 49 & 58 & 68 \\
\hline 46 & 36 & 42 & 49 & 58 & 68 \\
\hline 47 & 36 & 42 & 50 & 58 & 68 \\
\hline 48 & 36 & 42 & 50 & 59 & 69 \\
\hline 49 & 36 & 43 & 50 & 59 & 69 \\
\hline 50 & 36 & 43 & 50 & 59 & 69 \\
\hline 51 & 37 & 43 & 51 & 59 & 70 \\
\hline 52 & 37 & 43 & 51 & 60 & 70 \\
\hline 53 & 37 & 43 & 51 & 60 & 70 \\
\hline 54 & 37 & 44 & 51 & 60 & 71 \\
\hline 55 & 37 & 44 & 52 & 61 & 71 \\
\hline 56 & 37 & 44 & 52 & 61 & 71 \\
\hline 57 & 38 & 44 & 52 & 61 & 72 \\
\hline 58 & 38 & 44 & 52 & 61 & 72 \\
\hline 59 & 38 & 45 & 52 & 62 & 72 \\
\hline 60 & 38 & 45 & 53 & 62 & 73 \\
\hline 61 & 38 & 45 & 53 & 62 & 73 \\
\hline 62 & 39 & 45 & 53 & 63 & 73 \\
\hline 63 & 39 & 46 & 53 & 63 & 74 \\
\hline 64 & 39 & 46 & 54 & 63 & 74 \\
\hline
\end{tabular}


To be continued

ZVA

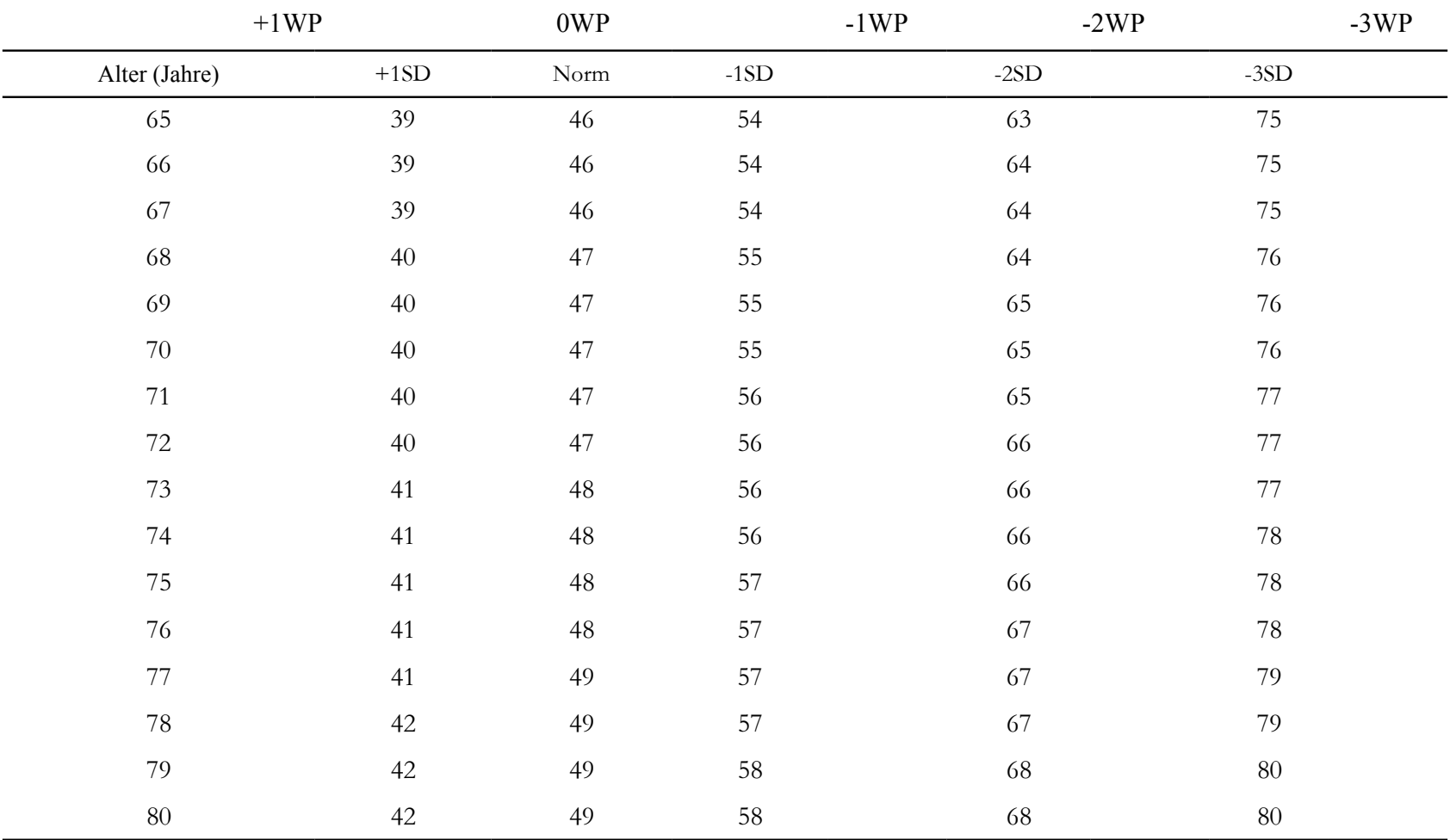

4d. Digit-symbol test (DST)

ZS

\begin{tabular}{ccccccc} 
& \multicolumn{2}{c}{ 0WP } & & -1 WP & -2 WP & -3 WP \\
\hline Alter (Jahre) & +1 SD & Norm & -1 SD & -2 SD & -3 SD \\
\hline 15 & 80 & 66 & 55 & 45 & 37 \\
16 & 79 & 65 & 54 & 45 & 37 \\
17 & 78 & 65 & 54 & 44 & 36 \\
18 & 77 & 64 & 53 & 43 & 36 \\
19 & 77 & 63 & 52 & 43 & 36 \\
20 & 76 & 63 & 52 & 43 & 35 \\
21 & 75 & 62 & 51 & 42 & 35 \\
22 & 74 & 62 & 51 & 42 & 34 \\
23 & 74 & 61 & 50 & 41 & 34 \\
24 & 73 & 60 & 50 & 41 & 33 \\
25 & 72 & 60 & 49 & 40 & 33 \\
26 & 72 & 59 & 49 & 40 & 33 \\
27 & 71 & 59 & 48 & 40 & 32 \\
28 & 70 & 58 & 48 & 39 & 32 \\
29 & 69 & 57 & 47 & 39 & 32 \\
30 & 69 & 57 & 47 & 38 & 31 \\
31 & 68 & 56 & 47 & 38 & 31 \\
32 & 67 & 56 & 46 & 38 & 31 \\
33 & 67 & 55 & 46 & 37 & 30 \\
34 & 66 & 55 & 45 & 37 & 30 \\
35 & 65 & 54 & 45 & 37 & 29 \\
36 & 65 & 54 & 44 & 36 & 36 & \\
37 & 64 & 53 & 44 & 36 & \\
38 & 63 & 52 & 43 & 43 & & \\
39 & 63 & 52 & & & 36 &
\end{tabular}


ZS

To be continued

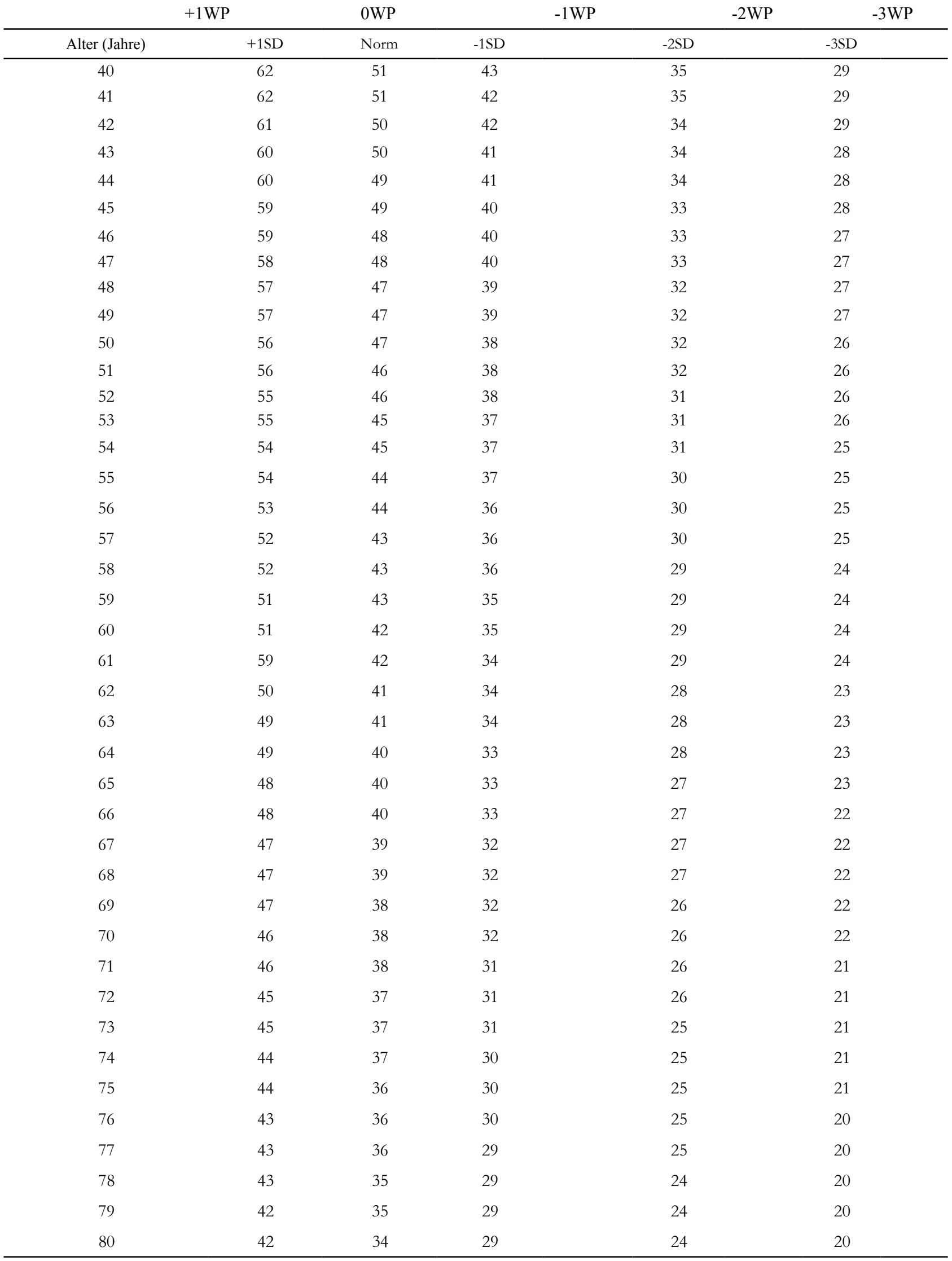




\section{Appendix 5. Brief visuospatial memory test-revised (BVMT-R)}

Brief Visuospatial Memory Test-Revised (BVMT-R): It contains 6 tests, each 2 points and totally 12 points. When the point is less than 6 points, it represents that the patient's construction ability is impaired.

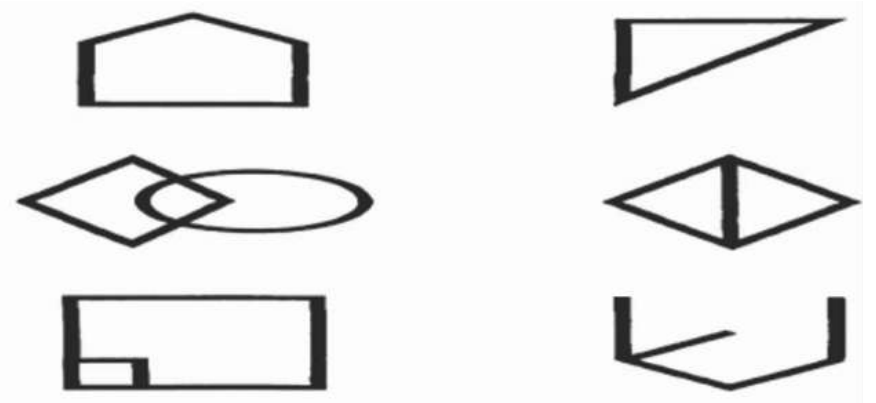

\section{Appendix 6. Clock Drawing Test (CDT)}

The patient is asked to draw a watch dial on white paper and mark the figures on corresponding positions and then point the watch hands to 8:20. Result judgment: 1 point for a closed circle; 1 point for marking figures on the proper positions; 1 point for marking all the 12 figures correctly; 1 point for pointing the watch hands to the proper position. The patient getting 0-1 points has severe HE, 2 points moderate HE and 3 points mild HE.

\section{Appendix 7. Mini-mental state examination (MMSE)}

Name: Gender: Endemic Area: Bed Number: In-patient Number: History of Smoking and Drinking ___ Other diseases: Diabetes___ Years, Hypertension___ years History of operation: _ History of other diseases

Education: University (and above), high school, junior school, elementary school and illiteracy

Dementia: No/Yes (mild, medium and heavy)

Clinical laboratory and examination:

Diagnosis:

Proposed surgery: Other:

Note:

Total Score: (Totally 30 points) Examiner: Date:

Serial No. Evaluated Items Correct Incorrect

* 1 . Now, I am to ask some questions to check your memory and calculation ability and most of them are very simple.

(1) What year is it?

(2) What season is it?

(3) What month is it?

(4) What date is it?

(5) What day is today?

(6) What city is it?

(7) What district is it?

(8) What hospital is it?

(9) What floor is it?

(10) Where is it and what department is it?

$\begin{array}{ll}1 & 0 \\ 1 & 0 \\ 1 & 0 \\ 1 & 0 \\ 1 & 0 \\ 1 & 0 \\ 1 & 0 \\ 1 & 0 \\ 1 & 0 \\ 1 & 0 \\ & \end{array}$

* 2. Now I tell you the names of three things, and please repeat them after I finish. Please remember these three things, then, I would like to ask you to repeat (carefully make it clear that everything, each a second). (Tell) These three things are: tree, bell and car. Repeat:

$\begin{array}{lll}\text { Tree } & 1 & 0 \\ \text { Bell } & 1 & 0 \\ \text { Car } & 1 & 0\end{array}$

* 3. Please calculate what 100 minus 7 is ? Then continue the calculation by subtracting 7 each time and tell me 
each answer until I say "stop".

\begin{tabular}{|c|c|c|}
\hline $100-7=93$ & 1 & 0 \\
\hline $93-7=86$ & 1 & 0 \\
\hline $86-7=79$ & 1 & 0 \\
\hline $79-7=72$ & 1 & 0 \\
\hline $72-7=65$ & 1 & 0 \\
\hline
\end{tabular}

4. Now, please speak out the three things that I just let you remember.

$\begin{array}{lll}\text { Tree } & 1 & 0 \\ \text { Clock } & 1 & 0 \\ \text { Car } & 1 & 0\end{array}$

5. (The examiner show his own watch)

Please tell me what it is?

1

(The examiner show his pencial)

Please tell me what it is?

1

*6. Please follow me: "Si Shi Si Zhi Shi Zi" $\quad 1 \quad 0$

7. (The examiner gives the test receiver a card with a sentence of "Please close your eyes!" on it) Please read the sentence and do as required:

0

8. I give you a piece of paper, and please do like I have told you. Now, begin!

Please hold the paper with your right hand

Fold it with two hands

110

Put the paper on your left leg

120

120

*9. Please write what you want to say to the doctor in a whole sentence: 1

0

* 10. Please draw the following figure:

1

0

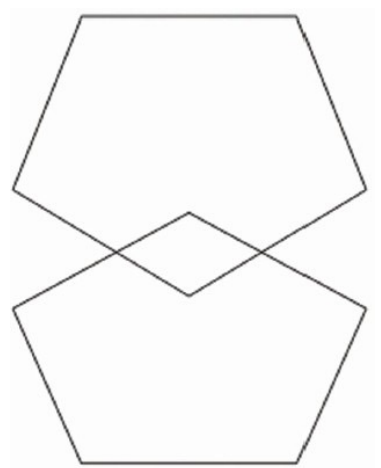

Notes:

*1. The total score ranges from 0 to 30 points and the normal and abnormal cutoff value is related to the level of education: illiterate group (uneducated) 17 points, primary school group (less than 6 years of education) 20 points, and middle school group and above (over 6 years of education) 24 points. If the points are below the cut-off value, cognitive dysfunctions can be confirmed, and above the cut-off value normal. In time of examination, the external interference should be avoided as much as possible. The elderly easily get discouraged and frustrated or give up, so more encouragement should be given to them. An examination generally needs 5 to 10 minutes.

*2. The examiner is only allowed to say once. The test receiver is not allowed make response according to the order of the articles. If there is error in the first time, score first. Tell the patient the error and to do once more, till he/she getting the right answer. But, the highest times should not exceed 5.

*3. This is the "sequential seven-subtraction" test in clinical treatment. Meanwhile, It can check the test receiver's attention. Do not repeat the answers for test and do not use pen for calculation. If one calculation is incorrect, the point for the calculation will be deducted. If the latter is correct, the point for it will be given. For instance: $100-7=93$ (correct, points given), 93-7 = 88 (incorrect, no points) and 88-7 = 81 (correct, points given)

* 6. Only 1 time is allowed, and only correct and clear pronunciation can get 1 point.

* 9. Sentence must have subject, predicate and meaning.

*10. One point is given only after two pentagon patterns and a quadrangle formed by the two pentagon patterns are drawn. 


\section{Appendix 8. Clinical hepatic encephalopathy staging scale (CHESS)}

This is a simple assessment method of the severity of HE. The total score is the sum of the answers to the nine items. Minimal score $=0$; maximal score $=9$.

\begin{tabular}{|c|c|c|c|}
\hline & \multirow{2}{*}{ Items } & \multicolumn{2}{|c|}{ Scores } \\
\hline & & 0 & 1 \\
\hline 1 & Does the patient know which month he/she is in (i.e. January, February)? & Yes & No, or he/she does not talk \\
\hline 2 & $\begin{array}{l}\text { Does the patient know which day of the week he/she is in (i.e., Thursday, Friday, } \\
\text { Sunday, etc.)? }\end{array}$ & Yes & No, or he/she does not talk \\
\hline 3 & Can he/she count backward from 10 to 1 without making mistakes or stopping? & Yes & No, or he/she does not talk \\
\hline 4 & If asked to do so, does he/she raise his/her arms? & Yes & No \\
\hline 5 & $\begin{array}{l}\text { Does he/she understand what you are saying to him/her? (based on the answers to } \\
\text { question } 1 \text { to } 4 \text { ) }\end{array}$ & Yes & No, or he/she does not talk \\
\hline 6 & Is the patient awake and alert? & Yes & No, he/she is sleepy or fast asleep \\
\hline 7 & Is the patient fast asleep, and is it difficult to wake him/her up? & No & Yes \\
\hline 8 & Can he/she talk? & Yes & $\mathrm{He} /$ she does not talk \\
\hline \multirow[t]{2}{*}{9} & $\begin{array}{l}\text { Can he/she talk correctly? In other words, can you understand everything he/she } \\
\text { says, and he/she doesn't stammer? }\end{array}$ & Yes & $\begin{array}{l}\text { No, he/she does not talk or does } \\
\text { not talk correctly }\end{array}$ \\
\hline & Total CHESS score: & & \\
\hline
\end{tabular}

